\title{
Glucosylsphingosine Promotes $\alpha$-Synuclein Pathology in Mutant GBA-Associated Parkinson's Disease
}

\author{
() Yumiko V. Taguchi, ${ }^{1,2}$ Jun Liu, ${ }^{3}$ ㅇiapeng Ruan, ${ }^{3}$ Joshua Pacheco, ${ }^{4}$ Xiaokui Zhang, ${ }^{4}$ Justin Abbasi, ${ }^{2,5}$ Joan Keutzer, ${ }^{4}$ \\ Pramod K. Mistry, ${ }^{3}$ and ${ }^{\circledR S}$ Sreeganga S. Chandra ${ }^{2,5,6}$ \\ ${ }^{1}$ Department of Cell Biology, ${ }^{2}$ Program in Cellular Neuroscience, Neurodegeneration and Repair, ${ }^{3}$ Department of Internal Medicine, ${ }^{5}$ Department of \\ Neurology, and ${ }^{6}$ Department of Neuroscience, Yale University School of Medicine, New Haven, Connecticut 06519, and ${ }^{4}$ Sanofi Genzyme, Framingham, \\ Massachusetts 01702
}

Glucocerebrosidase $1(G B A)$ mutations responsible for Gaucher disease (GD) are the most common genetic risk factor for Parkinson's disease (PD). Although the genetic link between GD and PD is well established, the underlying molecular mechanism(s) are not well understood. We propose that glucosylsphingosine, a sphingolipid accumulating in GD, mediates PD pathology in GBA-associated PD. We show that, whereas GD-related sphingolipids (glucosylceramide, glucosylsphingosine, sphingosine, sphingosine-1-phosphate) promote $\alpha$-synuclein aggregation in vitro, glucosylsphingosine triggers the formation of oligomeric $\alpha$-synuclein species capable of templating in human cells and neurons. Using newly generated GD/PD mouse lines of either sex [Gba mutant (N370S, L444P, K0) crossed to $\alpha$-synuclein transgenics], we show that $G b a$ mutations predispose to PD through a loss-of-function mechanism. We further demonstrate that glucosylsphingosine specifically accumulates in young GD/PD mouse brain. With age, brains exhibit glucosylceramide accumulations colocalized with $\alpha$-synuclein pathology. These findings indicate that glucosylsphingosine promotes pathological aggregation of $\alpha$-synuclein, increasing PD risk in GD patients and carriers.

Key words: $\alpha$-synuclein; GBA; glucosylsphingosine

\section{Significance Statement}

Parkinson's disease (PD) is a prevalent neurodegenerative disorder in the aging population. Glucocerebrosidase 1 mutations, which cause Gaucher disease, are the most common genetic risk factor for PD, underscoring the importance of delineating the mechanisms underlying mutant $G B A$-associated PD. We show that lipids accumulating in Gaucher disease, especially glucosylsphingosine, play a key role in PD pathology in the brain. These data indicate that ASAH1 (acid ceramidase 1) and GBA2 (glucocerebrosidase 2) enzymes that mediate glucosylsphingosine production and metabolism are attractive therapeutic targets for treating mutant $G B A$-associated PD.

\section{Introduction}

Parkinson's disease (PD) is a progressive neurodegenerative disease affecting $\sim 1 \%$ of the aging population (Nussbaum and Ellis, 2003). A key component of PD pathogenesis is $\alpha$-synuclein, a

Received June 1, 2017; revised Aug. 17, 2017; accepted Aug. 17, 2017.

Author contributions: Y.V.T., P.K.M., and S.S.C. designed research; Y.V.T., J.L., J.R., J.P., X.Z., J.A., and J.K. performed research; Y.V.T., P.K.M., and S.S.C. wrote the paper.

This work was supported by National Institute of Neurological Disorders and Stroke R01 NS064963, NS083846, and Regenerative Medicine Research Fund Grant 14-SCA-YALE-38 to S.S.C., and Sanofi Genzyme Center of Excellence in Clinical Translational Research Grant and National Institute of Arthritis and Musculoskeletal and Skin Diseases R01 AR 065932 to P.K.M. Y.V.T. was supported by the Cellular and Molecular Biology T32 GM007223 Training Grant and is presently a recipient of the National Institute of Neurological Disorders and Stroke T32 NS007224 Training Grant slot and the Lo Graduate Fellowship for Excellence in Stem Cell Research. We thank Dr. Arthur Horwich (Yale University) and members of our laboratories for reading the manuscript and giving suggestions; Dr. Li Gan (Gladstone/University of California-San Francisco) for generously providing the neurogenin-2 knock-in iPSC line; and Dr. David Russell (University of Texas Southwestern Medical Center) for generously sending the GBA2 S62 antibody.

P.K.M. has received research grants, travel support, lecture, and consultancy fees from Sanofi Genzyme. The other authors declare no competing financial interests. presynaptic protein normally functioning to regulate synaptic vesicle cycling (Chandra et al., 2003; Vargas et al., 2014). Point mutations in the SNCA gene, encoding $\alpha$-synuclein, cause autosomal dominant PD (A30P, A53T, A53E, E46K, H50Q, and G51D) (Polymeropoulos et al., 1997; Krüger et al., 1998; Zarranz et al., 2004; Lesage et al., 2013; Proukakis et al., 2013). Duplication and triplication of SNCA also cause PD (Singleton et al., 2003; Chartier-Harlin et al., 2004), highlighting the contribution of increased wild-type (WT) $\alpha$-synuclein levels to disease risk. The importance of $\alpha$-synuclein to PD was validated by the discovery that Lewy bodies, the pathological hallmarks of PD, con-

Correspondence should be addressed to either of the following: Dr. Pramod K. Mistry, Department of Internal Medicine, Yale University School of Medicine, New Haven, CT 06519. E-mail: pramod.mistry@yale.edu; and Dr. Sreeganga S. Chandra, Program in Cellular Neuroscience, Neurodegeneration and Repair, Yale University, New Haven, CT 06519. E-mail: sreeganga.chandra@yale.edu.

DOI:10.1523/JNEUROSCI.1525-17.2017

Copyright $\odot 2017$ the authors $\quad 0270-6474 / 17 / 379617-15 \$ 15.00 / 0$ 
sist mainly of aggregated $\alpha$-synuclein (Spillantini et al., 1997). While aggregated $\alpha$-synuclein present in Lewy bodies is fibrillar, recent studies have suggested that soluble oligomers are more toxic, largely contributing to PD-related neurodegeneration (Winner et al., 2011).

Mutations in $G B A$, encoding lysosomal glucocerebrosidase 1 (GCase1), are the most common genetic risk factor for PD (Sidransky et al., 2009). Biallelic mutations in GBA cause Gaucher disease (GD), a lysosomal storage disorder (Tsuji et al., 1987, 1988). The most common GCase1 mutations are N370S and L444P, accounting for 70\% of disease alleles (Charrow et al., 2000; Grabowski et al., 2014). Both GD patients and heterozygous carriers are at increased risk for $\mathrm{PD}$, with higher risk in homozygous individuals ( $\sim 20$-fold vs 5-fold, respectively) (Bultron et al., 2010; Alcalay et al., 2014). Hence, understanding the mechanistic links between GCase1 mutations and PD is of importance. GD patients develop Lewy body pathology, underscoring the importance of $\alpha$-synuclein aggregation in GD-associated PD (Wong et al., 2004). However, it is unclear how GCase1 mutations contribute to PD pathology. Indeed, several contradictory mechanisms have been proposed. It has been suggested that mutant GCase1 physically interacts with and induces acceleration of $\alpha$-synuclein aggregation in lysosomes (Yap et al., 2011), whereas another study showed that GCase1 loss-of-function-induced lysosomal dysfunction causes $\alpha$-synuclein aggregation in lysosomes, further perturbing its function (Mazzulli et al., 2011).

GCase 1 catalyzes the conversion of glucosylceramide (GlcCer) to glucose and ceramide. The primary defect in GD is the accumulation of GlcCer in lysosomes and is seen most prominently in macrophages. GlcCer is alternatively processed to glucosylsphingosine (GlcSph) via lysosomal acid ceramidase, which can readily exit the lysosome (see Fig. 1A) (Elleder, 2006; Hein et al., 2007; Ferraz et al., 2016). As GlcCer builds up, it spills over into the cytosol (Hein et al., 2007). GlcCer and GlcSph are well established as primary storage lipids in GD (Nilsson and Svennerholm, 1982). These cytosolic sphingolipids are hydrolyzed by nonlysosomal GCase2 (GBA2; not deficient in GD) (Yildiz et al., 2006), to ceramide, sphingosine (Sph), and sphingosine-1-phosphate (S1P). Ceramide does not accumulate due to hydrolysis by neutral ceramidase, resulting in secondary accumulation of Sph and S1P in GD. Together, lipids accumulating peripherally in GD are GlcCer, GlcSph, Sph, and S1P (Mistry et al., 2014). There is also evidence that loss of GCase1 activity leads to lysosomal dysfunction (Bae et al., 2015). While this cascade has been demonstrated in peripheral organs, presently it is not clear whether similar events occur in the brain.

Here, we propose that GlcCer and its metabolites are critical players in mutant GBA-associated PD. We show that sphingolipids accumulating in GD accelerate $\alpha$-synuclein aggregation in vitro, with potent effects of GlcSph and Sph in inducing pathologic $\alpha$-synuclein species capable of templating in human cells and neurons. Using newly generated Gba mutant (N370S, L444P) and knock-out (KO) mouse models crossed with an $\alpha$-synuclein transgenic PD mouse, we show that GCasel deficiency promotes $\alpha$-synuclein pathology. Importantly, we show that GlcSph accumulates in the brain of young GD mice, consistent with GlcSph being the toxic lipid species in mutant $G B A$ associated PD through initiation of pathological $\alpha$-synuclein aggregation.

\section{Materials and Methods}

Protein expression. Human WT $\alpha$-synuclein, along with the point mutants A30P and A53T, was purified as previously described (Chandra et al., 2003).
Liposome preparation. Liposomes were prepared using 75\% phosphatidylcholine (PC) and 25\% experimental lipid. For circular dichroism experiments seen in Figure 1, liposomes were prepared to a total concentration of $138 \mu \mathrm{M}$, or $34.5 \mu \mathrm{M}$ of experimental lipid. For circular dichroism experiments seen in Figure 6, liposomes were prepared to an experimental concentration of $0.1,1$, and $10 \mu \mathrm{M}$ of GlcSph with a constant $30 \mu \mathrm{M}$ PC for all conditions and PC control.

Experimental lipids include GlcSph (Matreya 1306), S1P (Sigma S9666), PC (Avanti Polar Lipids 840051P), ceramide (Avanti Polar Lipids 860052P), GM1 (Avanti Polar Lipids 860065P), bis(monoacylglycero) phosphate (BMP) (Avanti Polar Lipids 857136C), GlcCer (Avanti Polar Lipids 131304P), and Sph (Avanti Polar Lipids 860537P). Lipid was solubilized in 2:1 chloroform/methanol and dried in a glass tube using a gaseous nitrogen stream. Dried lipids were hydrated in $0.1 \mathrm{M}$ phosphate buffer, $\mathrm{pH} 7.4$ at $37^{\circ} \mathrm{C}$ for $1 \mathrm{~h}$, then vortexed for $5 \mathrm{~s}$ to form a liposome suspension. Liposomes were sonicated in a 2510 Branson ultrasonic cleaner bath for $30 \mathrm{~min}$ at $25^{\circ} \mathrm{C}$, put through 2 freeze/thaw cycles, then bath sonicated for another $60 \mathrm{~min}$. Liposome size was limited to $100 \mathrm{~nm}$ using a liposome extruder and used immediately. In the case of GM1 (Avanti Polar Lipids, 860065P), liposomes were not prepared using PC, as GM1 is soluble in aqueous solutions.

Circular dichroism. Circular dichroism was performed on a Chirascan spectrophotometer (wavelength range: $190-250 \lambda$, step size: $1 \lambda$, repeats: 3). Samples were prepared by mixing $138 \mu \mathrm{M}$ total lipid (or $34.5 \mu \mathrm{M}$ experimental lipid) to $13.8 \mu \mathrm{M} \alpha$-synuclein protein (lipid/protein $=$ 10:1) and protein/lipid mixtures were incubated at $37^{\circ} \mathrm{C}$, shaking at 1000 rpm. Circular dichroism was measured on freshly prepared samples and subsequently daily for $5 \mathrm{~d}$. Spectra were analyzed for secondary structure content following data acquisition using the DichroWeb CONTINLL database, reference set 7 (Provencher and Glöckner, 1981; van Stokkum et al., 1990; Lobley et al., 2002; Whitmore and Wallace, 2004, 2008).

Electron microscopy. The $3 \mu \mathrm{l} \alpha$-synuclein/lipid sample (prepared as described for circular dichroism) was added to carbon-coated grids (Electron Microscopy Sciences CF400-Cu) for 2 min at room temperature. Grids were washed once in $2 \%$ uranyl acetate, incubated in fresh $2 \%$ uranyl acetate for $1 \mathrm{~min}$, blotted, and allowed to air dry. Imaging of samples was performed on an FEI Tecnai G2 Spirit TWIN (T12).

Atomic force microscopy (AFM). AFM was performed on a Bruker Dimension Fastscan AFM using ScanAsyst Peak Force Tapping imaging mode. SCANASYST-AIR tips (Bruker Scientific) were used for imaging. The $4 \mu \mathrm{l}$ of $\alpha$-synuclein/lipid sample was added to freshly cleaved mica (Electron Microscopy Sciences 71856-01-10) and incubated at room temperature for $1 \mathrm{~min}$. Mica was washed twice with $50 \mu l$ deionized water to remove excess sample. Samples were then dried using nitrogen gas and imaged immediately after. Aggregate length was quantified using Image J software, with $n \geq 2$ images per condition.

Aggregation assay in HEK293T cells. HEK293T cells were transfected with human $\alpha$-synuclein-GFP (AddGene 40822 ) for $48 \mathrm{~h}$ using GenePORTER transfection reagent (Genlantis) in a 6-well plate. Confluent cells were then trypsin-isolated, with a final volume of $3 \mathrm{ml} /$ well cell suspension, in preparation for protein addition. The $0.2 \mathrm{mg} / \mathrm{ml}$ fibrillized or monomeric $\alpha$-synuclein was put through 3 freeze/thaw cycles and sonicated in a 2510 Branson ultrasonic cleaner bath for $10 \mathrm{~min} ; 25 \mu \mathrm{l}$ of sample was added to $100 \mu \mathrm{l}$ OptiMEM (Invitrogen), whereas $5 \mu \mathrm{l}$ of GenePORTER reagent was added to $100 \mu \mathrm{l}$ OptiMEM in a separate tube. Following $5 \mathrm{~min}$ incubation, the two mixtures were combined and allowed to incubate for $20 \mathrm{~min}$ at room temperature. The protein mixture was then added together with $200 \mu \mathrm{l}$ trypsin-isolated cell suspension of $\alpha$-synuclein-GFP HEK cells into one well of a 24 -well plate with a Matrigel-covered coverslip; $200 \mu$ l DMEM supplemented with $10 \%$ FBS was added $30 \mathrm{~min}$ after plating and grown for an additional $48 \mathrm{~h}$. Cells were then fixed with $4 \% \mathrm{PFA}, 4 \%$ sucrose solution for $40 \mathrm{~min}$ at $37^{\circ} \mathrm{C}$ for fluorescent imaging.

Quantitation of percentage of cells with aggregates was completed manually through random visualization of $\geq 90$ cells per biological replicate. Analysis was done blind to experimental condition.

Induced pluripotent stem cell (iPSC) differentiation into induced human neurons. Induced human neurons were produced through the forced expression of transcription factor neurogenin-2 in iPSCs, as previously 
described (Zhang et al., 2013). The Ngn2-iPSC line contains a single copy of a doxycycline-inducible mouse neurogenin 2 cassette (which also contained a CAG promoter driving a third-gen Tet transactivator) into the safe harbor AAVS1 locus of the parent WTC11 iPSC line. All induced neurons were used at least $30 \mathrm{~d}$ following differentiation.

Aggregation assay in induced human neurons. iPSCs were plated at a density of $100 \mathrm{cells} / \mathrm{cm}^{2}$ in 12 -well plates, differentiated as outlined above, and allowed to grow in culture for $30 \mathrm{~d} ; 0.2 \mathrm{mg} / \mathrm{ml}$ fibrillized or monomeric $\alpha$-synuclein was put through 3 freeze/thaw cycles and sonicated in a 2510 Branson ultrasonic cleaner bath for $10 \mathrm{~min} ; 50 \mu \mathrm{l}$ of sample was added to $200 \mu \mathrm{l}$ OptiMEM (Invitrogen), whereas $10 \mu \mathrm{l}$ of GenePORTER reagent was added to $200 \mu$ l OptiMEM in a separate tube. Following $5 \mathrm{~min}$ incubation, the two mixtures were combined and allowed to incubate for $20 \mathrm{~min}$ at room temperature. The protein mixture was then added to the media over the induced neurons and allowed to incubate at $37^{\circ} \mathrm{C}$ for $7 \mathrm{~d}$. Cells were then scraped and run on a Western blot for analysis of intracellular $\alpha$-synuclein levels.

Generation of mouse lines. Production of all GD lines is summarized in Figure 4. The insertion of a Neo cassette between exons 7 and 8 of $\mathrm{Gba}$ resulted in a complete $G b a \mathrm{KO}$, which was rescued in the skin using the K14-Cre as described by Mistry et al. (2010). Rescue in the skin prevented lethality, as $G b a \mathrm{KO}$ in the skin caused a disruption in the skin permeability barrier resulting in severe dehydration and early death. Gba mutant mice were generated by knocking in either Gba N370S (exon 9) or L444P (exon 10; L444P mice were a gift from Dr. Richard L. Proia) (Mizukami et al., 2002). Viable "homozygous" mutants possess one copy of Gba $\mathrm{N} 370 \mathrm{~S}$ or L444P and one copy of Gba KO with rescue in the skin.

Mouse genotyping was performed as follows: N370S genotyping ( 1 band at $414 \mathrm{bp}$ ), primers: N370S-forward (CAGTCACAGCATCATTACG), N370S-reverse (TTACGTGGTAAAGGAGGC); L444P genotyping ( 1 band at $381 \mathrm{bp}$ ), primers: L444P-forward (GCCAGTGAGAGCACTGACCC), L444P-reverse (GCCCCGTGTCACTGTAAGG); Neo/K14 genotyping ( 2 bands at $337 \mathrm{bp}$ (Neo) and $493 \mathrm{bp}$ (K14)), primers: GBA-forward (CCCGCTGGGCAGAGGTGGTA), Neo-reverse (GTGCCAGCGGGG CTGCTAAA), K14-forward (TTCCTCAGGAGTGTCTTCGC), K14reverse (GTCCATGTCCTTCCTGAAGC); Neo/WT genotyping (for differentiation of heterozygous vs homozygous Neo; 2 bands at $279 \mathrm{bp}$ (WT) and $313 \mathrm{bp}$ (Neo)), primers: GBA-forward (CCCGCTGGGCAGAGGTGGTA), GBA-reverse (ACCAGAGTTATCTGGTGAGATC).

Our Gba mice were produced similarly to Gba mice generated in Enquist et al. (2007), with some key differences that are likely to contribute to the relative viability of our lines. The insertion sites of the floxed neo differ (the insertion by Enquist et al., 2007 was between exons 8 and 9, whereas we inserted between exons 7 and 8 ), and in addition, there may be variations in the effectiveness of our K14-Cre mouse line.

All heterozygous and homozygous Gba KO, N370S, and L444P mice were crossed with mice overexpressing the human $\alpha$-synuclein A30P transgene, as previously described (Chandra et al., 2005). This cross was performed to overcome the issue of low penetrance of $\mathrm{PD}$ in GD patients, as GBA mutations only confer risk to, but do not cause, PD. All 14 resulting genotypes are listed in Figure $4 B$. Mice of either sex were used in all experiments.

GCase1 and GCase2 activity assay. A modified form of a previously established GCase assay was used in this paper (Mistry et al., 2010), with the following changes: decrease in buffer $\mathrm{pH}$, disuse of sodium taurocholate detergent, and the use of CBE and NB-DNJ inhibitors to determine baseline activity levels. All noted changes bettered assay accuracy.

One hemisphere of mouse brain was Dounce homogenized in $1 \mathrm{ml}$ homogenization buffer $(0.5 \%$ Triton X, 4 mM 2-ME, $0.05 \mathrm{M}$ citric acid, $0.1 \mathrm{M} \mathrm{K}_{2} \mathrm{HPO}_{4}$, pH 5.1 with $1 \times$ SIGMAFAST Protease Inhibitor Cocktail Tablet, Sigma-Aldrich S8830-20TAB) on ice at $3000 \mathrm{rpm}$ using 25 strokes. Homogenates were then put through 3 freeze/thaw cycles and spun at $14,000 \mathrm{rpm}$ for $20 \mathrm{~min}$ at $4^{\circ} \mathrm{C} ; 2 \mu \mathrm{l}$ of $5 \mu \mathrm{g} / \mu \mathrm{l}$ total protein from the supernatant and $2 \mu \mathrm{l}$ of GCase inhibitor (final concentration $36 \mu \mathrm{M}$ CBE to inhibit GCase1 or $10 \mu \mathrm{M}$ NB-DNJ to inhibit GCase2) was added to $21 \mu \mathrm{l}$ of GCase reaction buffer (4 mM 4-methylumbelliferyl-B-Dglucoside, $0.01 \% \mathrm{BSA}, 0.05 \mathrm{M}$ citric acid, $0.1 \mathrm{M} \mathrm{K}_{2} \mathrm{HPO}_{4}$, pH 5.1) for a total reaction volume of $25 \mu \mathrm{l}$. Reactions were incubated on ice for 30 $\mathrm{min}$, then at $37^{\circ} \mathrm{C}$ for $60 \mathrm{~min}$. Reaction was cooled to $4^{\circ} \mathrm{C}$ on ice and
$200 \mu \mathrm{l}$ of precooled stop solution ( $0.5 \mathrm{~m}$ glycine- $\mathrm{NaOH}, \mathrm{pH} 10.6)$ was added. Measurements were taken with a standard plate reader $(366 \mathrm{~nm}$ excitation, $445 \mathrm{~nm}$ emission). Standard curves were created using 8 concentrations of 4-methylumbelliferone standard ranging from 1 to $8 \mu \mathrm{M}$ prepared in $1 \%$ DMSO.

GCase1 levels were determined by subtracting GCase2 and background GCase activity levels (as determined through use of inhibitors: conduritol epoxide, CBE for Gbal and $\mathrm{N}$-butyl-deoxynojirimycin, NBDNJ for Gba2). Similarly, GCase2 levels were determined by subtracting GCase1 and background GCase activity levels (as determined through use of inhibitors). All inhibitors and baseline levels were prevalidated through the evaluation of $G b a \mathrm{KO}$ and $G b a 2 \mathrm{KO}$ mice as controls.

Characterization of mouse weight, behavior, and survival. Mouse weight was recorded monthly on a cohort containing 163 mice. Survival of all mouse lines was recorded over a 24 month period. Mice with severe dermatitis were censored, whereas mice suffering from end-stage motor phenotypes or those that were found dead were included in the analysis. Mouse behavior was characterized using the hanging grip test to assess motor phenotype. Mice able to hang for the complete 2:00 min are considered healthy, whereas those unable to hang for this amount of time exhibit motor phenotypes.

Immunohistochemistry. Brains were postfixed in 4\% PFA overnight, incubated in 30\% sucrose, and frozen in OCT. Brains were sectioned into $30 \mu \mathrm{m}$ free-floating sections using a Leica cryostat. Sections were washed in PBS, permeabilized in $0.5 \%$ Triton X-100 in PBS, and blocked in $0.1 \%$ Triton X-100 and 2\% goat serum in PBS for 30-60 min at room temperature. Sections were then incubated in primary antibody in blocking solution overnight at $4^{\circ} \mathrm{C}$, washed in PBS, and incubated in secondary antibody in blocking solution for $1 \mathrm{~h}$ at room temperature.

Whole spinal columns were postfixed in Cal-Rite decalcifying/fixation solution (Thermo Fisher Scientific 5501) for $2 \mathrm{~d}$. Spinal cords were dissected out, incubated in $30 \%$ sucrose for $2 \mathrm{~d}$, and frozen in OCT. Spinal cords were then sectioned into $7 \mu \mathrm{m}$ sections onto X-tra slides (Leica Biosystems 3800200) and dried for $10 \mathrm{~min}$. Slides were then washed in PBS for 5 min to remove OCT, permeabilized in $0.5 \%$ Triton X-100 in PBS, and blocked in $0.1 \%$ Triton X-100 and $2 \%$ goat serum in PBS for 30-60 min at room temperature. Slides were then incubated in primary antibody in blocking solution overnight at $4^{\circ} \mathrm{C}$, washed in PBS, and incubated in secondary antibody in blocking solution for $1 \mathrm{~h}$ at room temperature.

All samples were imaged using a Zeiss Laser Scanning Microscope 710. Primary antibodies include $\alpha$-synuclein (BD Biosciences 610786, RRID: AB_398107 at 1:500), CD68 (Bio-Rad MCA1957, RRID:AB_322219 at 1:500), glucosylceramide (Glycobiotech RAS0011 at 1:100), and phosphorylated $\alpha$-synuclein (Wako 015-25191, RRID:AB_2537218 at 1:1000). Goat AlexaFlour secondary antibodies were used at 1:500 dilution for all samples.

Nissl stain. Spinal cords for Nissl stain were treated and sectioned as outlined above. After drying, slides were washed in PBS 2 times for $5 \mathrm{~min}$, washed in water 1 time for $1 \mathrm{~min}$, incubated in $0.1 \%$ cresyl violet $/ 1 \%$ acetic acid for $20 \mathrm{~min}$, washed in water 2 times for $5 \mathrm{~min}$, then dipped in $90 \%, 95 \%$, and $100 \%$ ethanol. Slides were then cleaned in xylene 2 times, mounted using Permount (Fisher Scientific SP15-100), and allowed to dry overnight. Slides were imaged using an AmScope B490B-M Digital Compound Microscope.

Lipidomics. Lipidomics were completed as previously described (Mistry et al., 2014). Briefly, brain tissue samples were analyzed using an API 4000 triple-quadrupole mass spectrometer interfaced with an Agilent 1200 HPLC.

Differential detergent extraction. Total brain homogenate was serially extracted using detergents as outlined by Zhang et al. (2012). Serial extraction resulted in a soluble fraction (S1) and an SDS-insoluble fraction (P3), which were then analyzed by Western blot for phosphorylated $\alpha$-synuclein levels.

Dot blot on brain homogenate. A total of $5 \mu$ l of the soluble fraction (S1) from mouse brain serially extracted using detergents (see Differential detergent extraction) was blotted onto nitrocellulose membrane and allowed to dry for $1 \mathrm{~h}$ under vacuum. Membranes were blocked at room temperature for $1 \mathrm{~h}$, incubated in primary anti-oligomer A11 antibody 
(Invitrogen AHB0052, RRID:AB_2536236 at 1:1000) at room temperature for $1 \mathrm{~h}$, washed in TBST, incubated in secondary antibody for $1 \mathrm{~h}$ at room temperature, and washed in TBST before imaging.

ELISA on aggregated $\alpha$-synuclein. Concentration of total brain homogenate was determined using a BCA assay, and samples were diluted to 750 $\mathrm{ng} / \mathrm{ml}$ for use in ELISA. Samples were assayed using the Human $\alpha$-Synuclein PATHO ELISA kit (Analytikjena 847-0104[x]00108), specific for aggregated $\alpha$-synuclein.

Western blotting. Protein blots were run on 12\% acrylamide gels and transferred overnight onto PVDF transfer membrane. Membranes were blocked for $1 \mathrm{~h}$ at room temperature in $5 \% \mathrm{w} / \mathrm{v}$ milk and $5 \%$ goat serum in TBST. Membranes were then incubated overnight at $4^{\circ} \mathrm{C}$ in blocking buffer with primary antibody, washed in TBST, and incubated $1 \mathrm{~h}$ at room temperature in blocking buffer with secondary antibody. Primary antibodies include $\alpha$-synuclein (BD Biosciences 610786, RRID:AB_398107 at 1:1000), actin (MP Biomedicals 691001, RRID:AB_2336056 at 1:10,000), GCase1 (Sigma G4171, RRID:AB_1078958 at 1:100), and GCase2 (S62 at 1:1000) (Yildiz et al., 2006), phosphorylated $\alpha$-synuclein (Wako 015-25191, RRID: AB_2537218 at 1:1000), and acid ceramidase (Santa Cruz Biotechnology SC-292176, RRID:AB_10918357 at 1:100). LI-COR Goat IRDye secondary antibodies were used at 1:6000 dilution for all samples.

Immunofluorescence. Induced human neurons were fixed using $4 \%$ $\mathrm{PFA}, 4 \%$ sucrose for $40 \mathrm{~min}$ at $37^{\circ} \mathrm{C}$ for fluorescent imaging. Cells were washed in PBS, blocked in $3 \%$ goat serum and $0.3 \%$ Triton X-100 in PBS, and incubated in blocking buffer with primary antibody overnight at $4^{\circ} \mathrm{C}$. Cells were then washed in PBS and incubated in blocking buffer with secondary antibody for $1 \mathrm{~h}$ at room temperature. Primary antibodies include $\alpha$-synuclein (BD Biosciences 610786, RRID:AB_398107 at 1:500), CSP $\alpha$ (Enzo ADI-VAP-SV003-E, RRID:AB_10532399 at 1:1000), and MAP2 (EMD Millipore AB5543, RRID:AB_571049 at 1:5000). Goat AlexaFlour secondary antibodies were used at 1:500 dilution for all samples.

Lysosomal fractionation. Lysosomal fractionation was performed using the Lysosome Enrichment Kit for Tissue and Cultured Cells (Thermo Fisher Scientific 89839); $N=3$ brains per condition.

\section{Experimental design and statistical analysis}

For all mouse experiments, both sexes were used.

Circular dichroism experiments (see Figs. 1, 6F). One-tailed $t$ test used to test significance relative to PC. Three replicates of each condition were run. For Figure $1 E, p$ values: GlcCer $=0.005, \mathrm{GlcSph}=0.016, \mathrm{Sph}=$ $0.024, \mathrm{~S} 1 \mathrm{P}=0.028$, Cer $=0.353$; for Figure $1 F, p$ values: $\mathrm{BMP}=0.003$, $\mathrm{GM} 1=6.778 \times 10^{-5}$; for Figure $1 G, p$ values: GlcCer $=0.320, \mathrm{GlcSph}=$ $0.003, \mathrm{Sph}=0.002, \mathrm{~S} 1 \mathrm{P}=0.049$, and $\mathrm{Cer}=0.262$; for Figure $1 H, p$ values: GlcCer $=0.369, \mathrm{GlcSph}=0.012, \mathrm{Sph}=0.003, \mathrm{~S} 1 \mathrm{P}=8.0319 \times$ $10^{-4}$, and Cer $=0.481$. For Figure $6 F$, day $7 p$ values: GlcSph-0.1 $=$ 0.243 , GlcSph-1 $=0.472$, GlcSph-10 = 0.004 .

Aggregation assay in HEK293T cells (see Fig. 3A). Two-tailed $t$ test used to test significance relative to $\mathrm{PC} ; \geq 241$ cells per condition were assayed. $p$ values: $\mathrm{Cer}=1.000, \mathrm{GM} 1=0.423, \mathrm{GlcCer}=0.301, \mathrm{GlcSph}=0.014$, $\mathrm{Sph}=4.900 \times 10^{-4}, \mathrm{~S} 1 \mathrm{P}=0.298$.

Aggregation assay in human neurons (see Fig. $3 B$ ). Two-tailed $t$ test was used to test significance relative to PC. Two replicates of each condition were run. $p$ values: $\mathrm{Cer}=0.894, \mathrm{GM} 1=0.544$, GlcCer $=0.910$, $\mathrm{GlcSph}=0.021, \mathrm{Sph}=5.500 \times 10^{-4}, \mathrm{~S} 1 \mathrm{P}=0.867$.

Gba protein levels in brain (see Fig. $4 D$ ). Two-tailed $t$ test used to test significance. Two replicates of each conditions were run. $p$ values versus $\mathrm{WT}: \mathrm{L} 444 \mathrm{P} / \mathrm{WT}=0.127, \mathrm{~N} 370 \mathrm{~S} / \mathrm{WT}=0.626, \mathrm{KO} / \mathrm{WT}=0.230, \mathrm{~L} 444 \mathrm{P} /$ $\mathrm{KO}=0.002, \mathrm{~N} 370 \mathrm{~S} / \mathrm{KO}=0.003, \mathrm{KO} / \mathrm{KO}=0.001 . p$ values versus $\mathrm{N} 370 \mathrm{~S} / \mathrm{KO}: \mathrm{L} 444 \mathrm{P} / \mathrm{KO}=0.010, \mathrm{KO} / \mathrm{KO}=0.001$.

Gba activity levels in brain (see Fig. $4 E, F$ ). Two-tailed $t$ test used to test significance. For total Gba activity levels, 17 WT, 35 GBA Het, and 24 GBA KO mice were assayed. $p$ values versus WT: Het $=0.008, \mathrm{KO}=$ $3.658 \times 10^{-13} ; p$ values versus Het: $\mathrm{KO}=2.577 \times 10^{-19}$. For age-related Gba activity levels, 6 young WT, 9 old WT, 22 young GBA Het, 10 old GBA Het, 13 young GBA KO, and 9 old GBA KO mice were assayed. Two-tailed $t$ tests were used to test significance. $p$ values versus corresponding young cohort: $\mathrm{WT}=0.170$, Het $=0.003, \mathrm{KO}=0.753$.
Assessment of lumbar motor neurons in spinal cord (see Fig. 5B). Twotailed $t$ tests were used to test significance relative to WT. $N$ and $p$ values: WT/WT: $N=3$; /WT: $N=2, p=0.489 ; / \mathrm{KO}: N=5, p=0.144 ; \mathrm{SNCA}^{\mathrm{Tg}}$ : $N=2, p=0.002$; /WT SNCA ${ }^{\mathrm{Tg}}: N=2, p=0.009 ; / \mathrm{KO} \mathrm{SNCA}^{\mathrm{Tg}}: N=3$, $p=0.001$.

Assessment of microglia recruitment in $S N C A^{T g}$ mice (see Fig. 5D). Twotailed $t$ tests were used to test significance relative to WT. $N$ and $p$ values: WT/WT: $N=5$; /WT: $N=2, p=0.315$; /KO: $N=1$, no $p$ value; $\mathrm{SNCA}^{\mathrm{Tg}}: N=2, p=0.005$; $/ \mathrm{KO} \mathrm{SNCA}^{\mathrm{Tg}}: N=3, p=0.001$.

Motor phenotype onset to death in GD/PD mice (see Fig. $5 H$ ). Twotailed $t$ tests were used to test significance of GD/PD early death mice relative to WT mice; $N=10$ for both groups. $p$ value relative to $\mathrm{PD}=$ $1.64 \times 10^{-4}$.

Lipidomics on mouse brain (see Fig. 6A-D). Two-tailed $t$ tests were used to test significance relative to WT. $N$ for all analyses: WT/WT: 3, L444P/ WT: 3, N370S/WT: 2, KO/WT: 2, L444P/KO: 2, N370S/KO: 6, KO/KO (GlcSph Only): 1. $p$ value for GlcSph levels: L444P/WT $=0.234, \mathrm{~N} 370 \mathrm{~S} /$ $\mathrm{WT}=0.313, \mathrm{KO} / \mathrm{WT}=0.608, \mathrm{~L} 444 \mathrm{P} / \mathrm{KO}=3.350 \times 10^{-4}, \mathrm{~N} 370 \mathrm{~S} /$ $\mathrm{KO}=0.002$.

GlcSph-derived $\beta$-sheeted $\alpha$-synuclein (see Fig. $6 F$ ). Two-tailed $t$ tests were used to test significance relative to WT; $N=3$ for all samples. $p$ value relative to PC: GlcSph- $0.1=0.243$, GlcSph- $1=0.472$, GlcSph$10=0.004$.

Concentration of lysosomal fractions (see Fig. 6I). Two-tailed $t$ tests were used to test significance of $G b a{ }^{/ \mathrm{KO}}$ relative to WT; $N=3$ for both groups. $p$ value relative to $\mathrm{WT}=0.031$.

GlcCer standard curve (see Fig. $6 J$ ). Standard curve with samples containing $0,0.2,0.5,1$, and $2 \mu \mathrm{g}$ GlcCer were plotted and yielded an $R^{2}=$ 0.99 .

GlcCer levels in brain by antibody (see Fig. $7 \mathrm{~B}, C$ ). Two-tailed $t$ tests were used to test significance relative to WT/WT. For Figure $7 B, N$ and $p$ values: anticipated death: $N=3$; early death: $N=3, p=0.013$. For Figure $7 C, N$ and $p$ values: WT/WT: $N=3$; $\mathrm{SNCA}^{\mathrm{Tg}}: N=3, p=0.624$; /WT $\mathrm{SNCA}^{\mathrm{Tg}}: N=4, p=0.783$; $/ \mathrm{KO} \mathrm{SNCA}^{\mathrm{Tg}}: N=3, p=0.010$.

Phosphorylated $\alpha$-synuclein $S 129$ levels by antibody (see Fig. $7 D, H$ ). One-tailed $t$ tests were used to test significance relative to WT/WT. For Figure $7 D, N$ and $p$ values: WT/WT: $N=3$; $\mathrm{SNCA}^{\mathrm{Tg}}: N=3, p=0.010$; /WT SNCA ${ }^{\mathrm{Tg}}: N=4, p=0.036$; $/ \mathrm{KO} \mathrm{SNCA}^{\mathrm{Tg}}: N=3, p=0.010$. For Figure $7 \mathrm{H}(16 \mathrm{kDa}), N$ and $p$ values versus WT/WT: $\mathrm{SNCA}^{\mathrm{Tg}}: N=3, p=$ $4.120 \times 10^{-4}$; $/ \mathrm{KO} \mathrm{SNCA}^{\mathrm{Tg}}: N=3, p=0.008$. For Figure $7 \mathrm{H}(37 \mathrm{kDa})$, $N$ and $p$ values versus WT/WT: SNCA ${ }^{\mathrm{Tg}}: N=3, p=0.090$; $/ \mathrm{KO} \mathrm{SNCA}^{\mathrm{Tg}}$ : $N=3, p=0.002$.

Aggregated $\alpha$-synuclein levels by ELISA (see Fig. 7J). Two-tailed $t$ tests were used to test significance relative to WT/WT. $N$ and $p$ values: WT/ WT: $N=3 ;$ SNCA $^{\mathrm{Tg}}: N=3, p=0.016 ; / \mathrm{KO} \mathrm{SNCA}^{\mathrm{Tg}}: N=3, p=0.014$; $p$ values versus $\mathrm{SNCA}^{\mathrm{Tg}}$ : $/ \mathrm{KO}^{\mathrm{SNCA}}{ }^{\mathrm{Tg}}=0.034$.

GBA2 activity levels in mouse brain (see Fig. $8 A$ ). Two-tailed $t$ tests were used to test significance relative to young cohort. $N$ and $p$ values: WT/ WT: $N=8$, 3-month, 91 -year mice, $p=0.507$; $/ \mathrm{WT}: N=263$-month, 91 -year mice, $p=0.038$; $/ \mathrm{KO}: N=163$-month, 81 -year mice, $p=0.398$.

GBA2 protein levels in mouse brain (see Fig. $8 C$ ). Two-tailed $t$ tests were used to test significance relative to young cohort. Six mice per genotype were used, with 3 young (age 3 months) and 3 old (age $1+$ year) mice. $p$ values: $\mathrm{WT} / \mathrm{WT}=0.193$, $/ \mathrm{WT}=0.021, / \mathrm{KO}=0.991$.

\section{Results \\ Sphingolipids accumulating in GD promote $\alpha$-synuclein aggregation into distinct pathologic species in vitro}

To determine whether the sphingolipids that accumulate peripherally in GD, GlcCer, GlcSph, Sph, and S1P interact with $\alpha$-synuclein and influence its aggregation, we used circular dichroism to track the secondary structure of $\alpha$-synuclein in the presence of respective lipids. To mimic a cellular setting, PC liposomes containing one of the following lipids: GlcCer, GlcSph, Sph, S1P, ceramide, GM1 ganglioside, or BMP (a major component of lysosomal membranes) were prepared and incubated with purified human WT $\alpha$-synuclein. PC alone serves as a negative control as it does not alter the conformations of 
A Glucosylceramide Metabolism

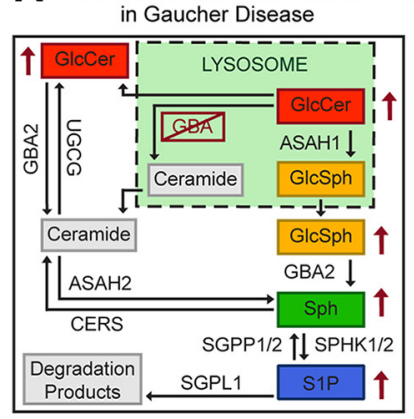

B Induced Secondary Structure

\begin{tabular}{|l|l|l|}
\hline \multicolumn{2}{|c|}{ Lipid } & \multicolumn{2}{c|}{ Day 0 } & \multicolumn{1}{c|}{ Day 5 } \\
\hline PC & Unstructured & Unstructured \\
Cer & Unstructured & Unstructured \\
BMP & $\alpha$-Helical & $\alpha$-Helical \\
GM1 & $\alpha$-Helical & $\alpha$-Helical \\
GlcCer & Unstructured & $\beta$-Sheeted \\
GlcSph & Unstructured & $\beta$-Sheeted \\
Sph & Unstructured & $\beta$-Sheeted \\
S1P & Unstructured & $\beta$-Sheeted \\
\hline
\end{tabular}

C
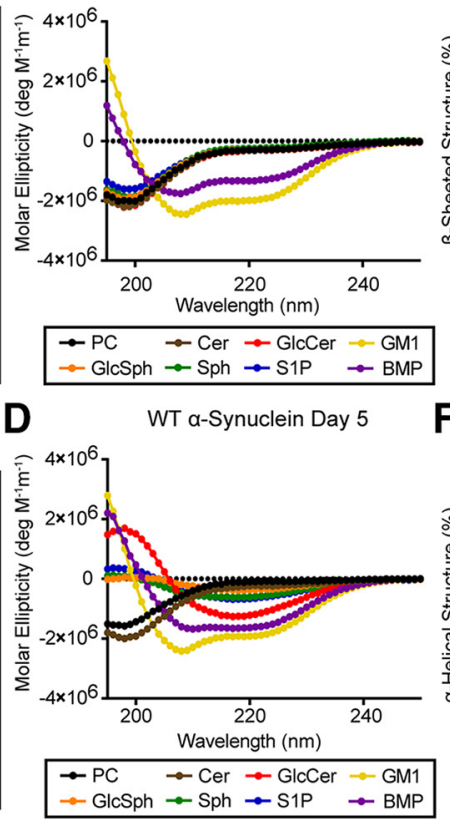

E

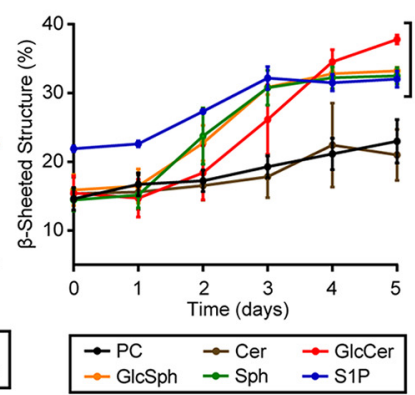

$\alpha$-Helical WT a-Synuclein

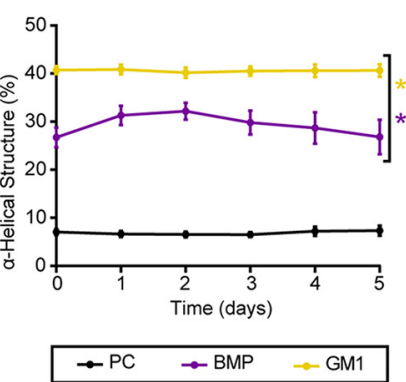

G
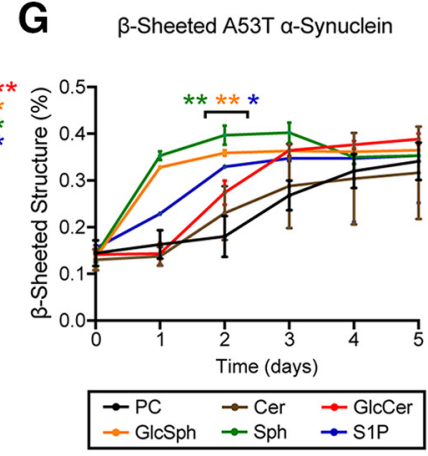

$\mathbf{H}$

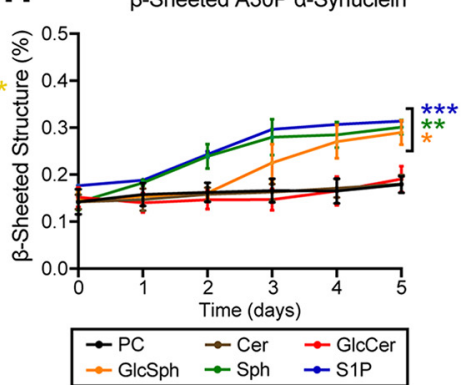

Figure 1. Sphingolipids accumulating in GD promote the acceleration of $\alpha$-synuclein aggregation into different pathologic species. $\boldsymbol{A}$, Spatial topography of GIcCer metabolism in GD with reference to subcellular compartmentalization of enzymes and sphingolipids. Red upward arrows indicate upstream and downstream sphingolipids that accumulate peripherally due to GBA deficiency. Green zone represents lysosome. $\boldsymbol{B}$, Summary of circular dichroism results obtained by incubating $\alpha$-synuclein with the indicated lipids for 5 d. For all circular dichroism data, experimental lipids were added at $34.5 \mu \mathrm{m}$ and $\alpha$-synuclein added at $13.8 \mu \mathrm{m}$ [(total lipid PC + experimental lipid liposome): protein = 10:1]. C, Circular dichroism spectra of WT $\alpha$-synuclein at day 0. Unfolded proteins have minima at $195 \mathrm{~nm}$, whereas $\alpha$-helical conformations have minima at 205 and $222 \mathrm{~nm}$. D. Circular dichroism spectra of WT $\alpha$-synuclein at day 5 . Proteins with $\beta$-sheeted conformations have minima at $217 \mathrm{~nm}$. $\boldsymbol{E}$, Time course of $\beta$-sheet conformation acquisition of WT $\alpha$-synuclein in presence of GD sphingolipids. The percentage $\beta$-sheet conformation was calculated using DichroWeb. $p$ values relative to $\mathrm{PC}$ for GlcCer $=0.005, \mathrm{Gl} \mathrm{Sph}=0.016, \mathrm{Sph}=0.024, \mathrm{S1P}=0.028$, and Cer $=0.353$. $F$, Time course of $\alpha$-helical conformation acquisition in the presence of GM1 and BMP. $p$ values relative to $\mathrm{PC}$ for BMP $=0.003, \mathrm{GM1}=6.778 \times 10^{-5}$. G, Time course of $\beta$-sheet conformation acquisition of mutant A53T $\alpha$-synuclein in presence of same sphingolipids. $p$ values relative to $\mathrm{PC}$ for $\mathrm{GlCCer}=0.320, \mathrm{Gl} \mathrm{Sph}=0.003, \mathrm{Sph}=0.002, \mathrm{S1P}=0.049$, Cer $=0.262$. $F$, Time course of $\beta$-sheet conformation acquisition of mutant A30P $\alpha$-synuclein in presence of same sphingolipids. $p$ values relative to $\mathrm{PC}$ for GlcCer $=0.369, \mathrm{Gl} \mathrm{Sph}=0.012, \mathrm{Sph}=0.003, \mathrm{~S} 1 \mathrm{P}=8.0319 \times 10^{-4}, \mathrm{Cer}=0.481 . \boldsymbol{E}-\boldsymbol{H}$, Data are mean \pm SEM. $n=3$ experiments per sample, ${ }^{*} p<0.05$ versus $P C$ (one-tailed Student's $t$ test). ${ }^{* *} p<0.01$ versus $P C$ (one-tailed Student's $t$ test). ${ }^{* *} p<0.001$ versus $P C$ (one-tailed Student's $t$ test).

$\alpha$-synuclein, whereas GM1 is a positive control for inducing an $\alpha$-helical conformation (Martinez et al., 2007). Circular dichroism spectra were measured immediately after mixing and subsequently daily for $5 \mathrm{~d}$. On day $0, \alpha$-synuclein was unstructured in the presence of all lipids, except GM1 and BMP, both of which induced an $\alpha$-helical conformation upon mixing (Fig. $1 B, C, F$ ). Secondary structure was analyzed for the emergence of $\beta$-sheet structure, indicative of transition from unstructured, monomeric, $\alpha$-synuclein to oligomers or fibrils. After $5 \mathrm{~d}$ of incubation, $\alpha$-synuclein samples containing GD-associated sphingolipids were mainly $\beta$-sheeted (Fig. $1 B, D, E$ ), whereas samples with PC and Cer remained unstructured and samples with GM1 ganglioside and BMP remained $\alpha$-helical (Fig. $1 B, D, F$ ). Of the GD sphingolipids, GlcCer was the slowest to induce $\beta$-sheet structure formation (Fig. $1 E, G, H$ ). Incubation with GlcCer has been previously shown to accelerate $\alpha$-synuclein aggregation, supporting our findings (Mazzulli et al., 2011). These results clearly show that all sphingolipids that accumulate in GD can interact with WT $\alpha$-synuclein to accelerate its aggregation into oligomeric and/or fibrillary states. We obtained similar results with PD mutants of $\alpha$-synuclein (A53T, A30P) (Fig. 1G,H).

To differentiate between oligomer and fibril formation in the circular dichroism samples, we performed electron microscopy and AFM to visualize the $\alpha$-synuclein aggregates formed in the presence of our experimental lipids (day 5 samples). Using electron microscopy, we found $\alpha$-synuclein fibrils in samples containing GlcCer, Sph, and S1P, whereas unfibrillized protein was present in other samples (Fig. 2A). The fibrils were typical of those seen when $\alpha$-synuclein alone is aggregated in vitro (Fig. 2A) or purified from transgenic mice (Recasens et al., 2014; Peelaerts et al., 2015). Interestingly, we did not see long fibrils in the presence of GlcSph (Fig. 2A), even though GlcSph induced $\beta$-sheet structure as measured by circular dichroism (Fig. $1 B, D, E$ ). To further elucidate the type of $\alpha$-synuclein aggregates formed in the presence of GlcSph, we imaged these samples with AFM. Intriguingly, we discovered oligomers in the GlcSph sample (Fig. 2B). We also confirmed the presence of long fibrils in the GlcCer and S1P samples using this method, and identified that Sph induces a heterogeneous mixture of oligomers and fibrils (Fig. 2B). When we measured the length of the $\alpha$-synuclein species, we can clearly differentiate the ones formed by GlcSph and Sph (Fig. 2C), which have a median length of 0.043 and $0.104 \mu \mathrm{m}$, respectively, from those formed by GlcCer and S1P, which have a median length of 0.603 and $0.582 \mu \mathrm{m}$ (Fig. 2D). These findings demonstrate a direct role of GlcCer, GlcSph, Sph, and S1P in promoting $\alpha$-synuclein aggregation into different types of species, further suggesting that some of these sphingolipids may be more pathological than others within the nervous system.

$\alpha$-Synuclein species produced by GlcSph and Sph have distinctive aggregation propensity in mammalian cell culture and human neurons

We established an intracellular $\alpha$-synuclein aggregation assay in HEK293T cells based on previous literature (Luk et al., 2009). 
A Electron Microscopy

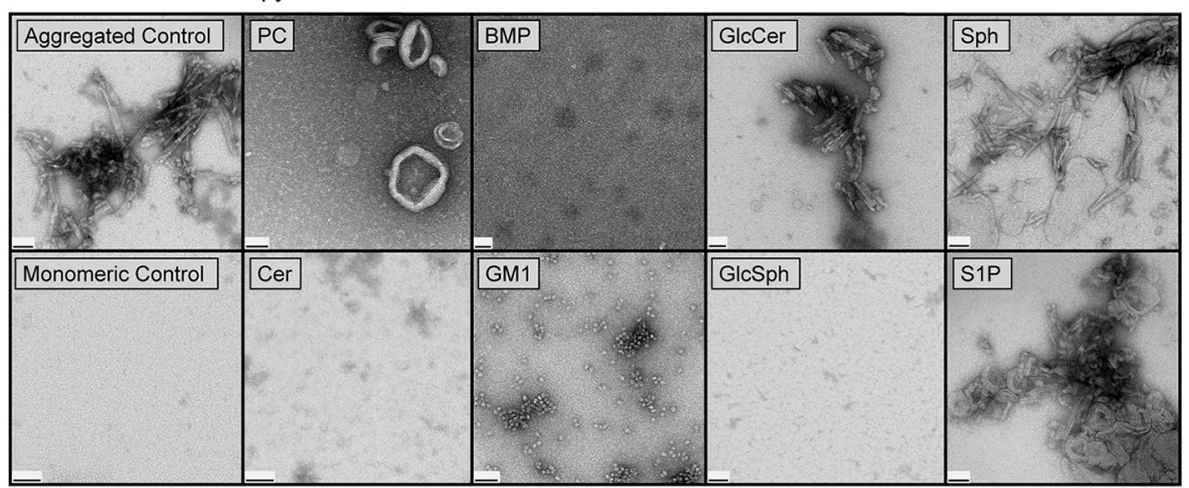

B Atomic Force Microscopy

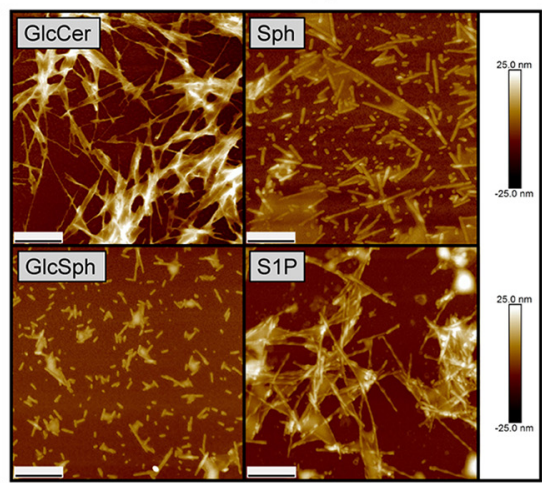

C Quantification of Length of Aggregates Produced from Gaucher Lipids
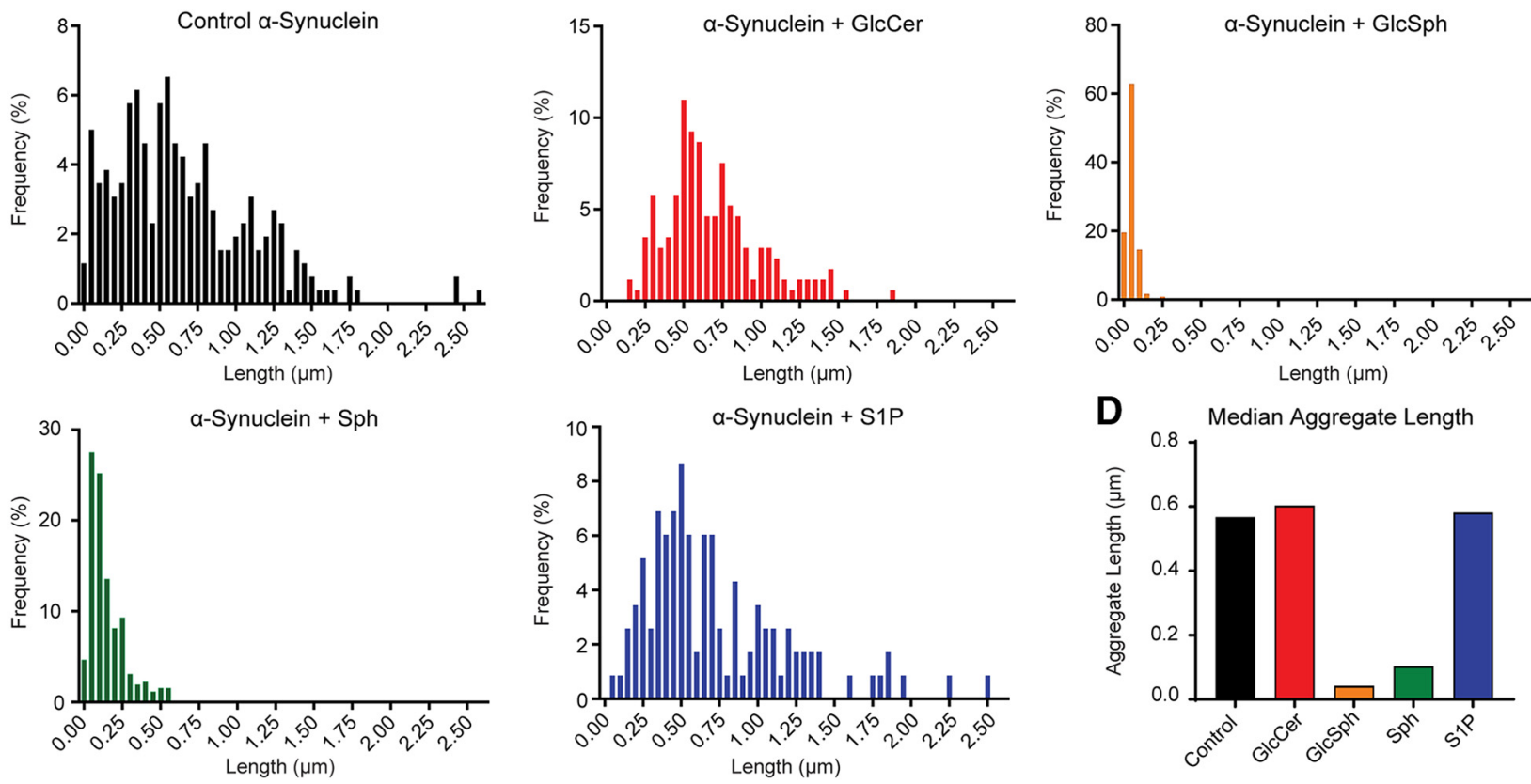

Figure 2. GlcSph and Sph promote oligomeric $\alpha$-synuclein aggregates. $\boldsymbol{A}$, Electron microscopy images of day 5 circular dichroism samples. Left panels, Images of monomeric and aggregated $\alpha$-synuclein are shown for reference. Scale bar, $50 \mathrm{~nm}$. B, AFM images of $\alpha$-synuclein aggregated with Gaucher sphingolipids. Scale bar, $500 \mathrm{~nm}$. Height of images $=50 \mathrm{~nm}$. $N=3 \mathrm{independent}$ experiments. $\boldsymbol{C}$, Frequency distribution of size of $\alpha$-synuclein species formed by aggregation in vitro as analyzed by AFM. Control conditions are in the absence of lipids, but aggregated for longer durations. The GD sphingolipids used are denoted. There are three images/condition. D, Median length of $\alpha$-synuclein species formed.

Briefly, we added preformed $\alpha$-synuclein aggregates to the culture media of HEK293T cells overexpressing $\alpha$-synuclein-GFP, facilitated internalization, and monitored templating of endogenous $\alpha$-synuclein-GFP into intracellular, GFP-positive aggregates (Fig. 3A). This assay was used to evaluate the relative pathogenicity of aggregated species formed following $\alpha$-synuclein incubation with GD-associated sphingolipids. We found that preformed aggregated $\alpha$-synuclein species formed with GlcSph and Sph produced significantly more internal, GFP-positive aggregates than with GlcCer and S1P, related lipids, and controls (Fig. 3A). Notably, the templating propensity of the preformed aggregated species correlated with the oligomeric $\alpha$-synuclein structures observed by AFM in the samples containing GlcSph and Sph (Fig. $2 B-D$ ). Although we cannot exclude the possibility that oligomeric $\alpha$-synuclein species are taken up more efficiently, it would still suggest that size of $\alpha$-synuclein species formed is a determinant of its pathogenicity. These results show a specific effect of GlcSph and Sph in inducing the formation of oligomeric $\alpha$-synuclein species that are capable of pathologic templating.
To confirm these results in a neuronal model, we used human neurons derived from iPSCs. Differentiation was induced through neurogenin 2 expression, generating excitatory neurons, as described previously (Zhang et al., 2013). Consistent with previous reports, the human neurons show localization of $\alpha$-synuclein at presynaptic puncta and MAP2-positive dendrites. Similar to our experiments in HEK293T cells, we added exogenous preformed GD sphingolipid-induced $\alpha$-synuclein species and assessed their effects on internal $\alpha$-synuclein aggregation. By Western blotting, we could show that samples with GlcSph and Sph specifically promoted endogenous $\alpha$-synuclein aggregation, whereas samples with GlcCer, S1P, and control lipids resulted in only monomeric $\alpha$-synuclein (Fig. $3 B$ ). The aggregation observed is unlikely to be remnants of exogenous $\alpha$-synuclein species as we do not see any aggregates in GlcCer and S1P samples, even though they are likely to be stable. These results in neuronal cells replicate our findings in HEK293T culture, verifying that oligomeric $\alpha$-synuclein species formed with GlcSph and Sph are more pathogenic in hu- 
A Addition of a-Synuclein with Gaucher Lipids to HEK293T Cells
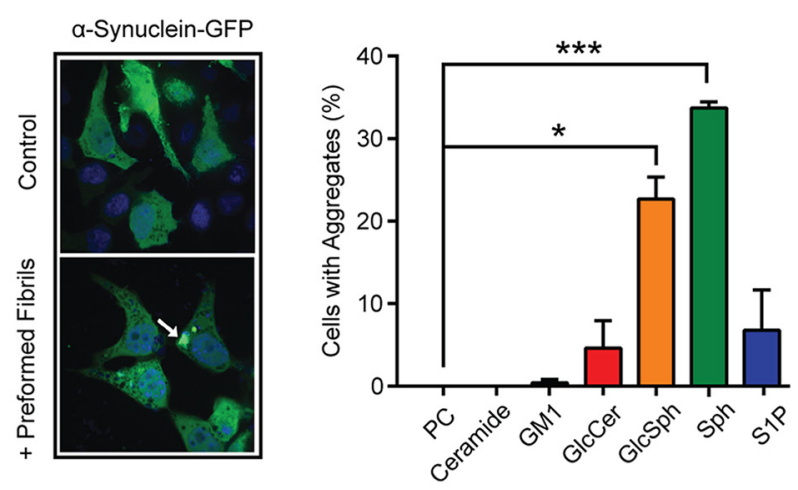

B

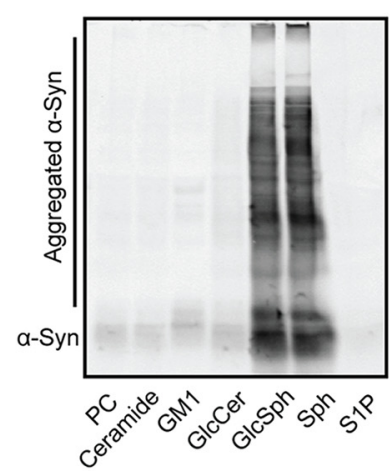

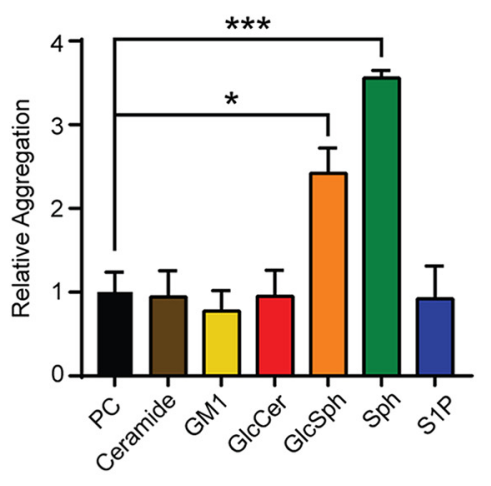

Figure 3. Oligomeric GlcSph and Sph $\alpha$-synuclein species promote $\alpha$-synuclein seeding. $\boldsymbol{A}$, Intracellular $\alpha$-synuclein aggregation assay in HEK293T cells, in which $\alpha$-synuclein species aggregated in the presence of various lipids were added to cell media with a bioporter. Arrow indicates aggregated $\alpha$-synuclein-GFP. Quantification shown for percentage of HEK293T cells with intracellular aggregates when templated with GD-related sphingolipid preformed $\alpha$-synuclein species. $N=3$ experiments with $\geq 241$ cells per condition were assayed. $p$ values relative to PC: $\mathrm{Cer}=1.000, \mathrm{GM1}=0.423, \mathrm{GlcCer}=0.301, \mathrm{GlCSph}=0.014, \mathrm{Sph}=4.900 \times 10^{-4}, \mathrm{~S} 1 \mathrm{P}=0.298 . \boldsymbol{B}$, Intracellular $\alpha$-synuclein aggregation assay as performed in human neurons. Quantification of relative aggregation, higher molecular weight species normalized to monomeric $\alpha$-synuclein. $N=2$ experiments. $p$ values relative to PC: $C$ er $=0.894, \mathrm{GM} 1=0.544, \mathrm{GlcCer}=0.910, \mathrm{Gl} \mathrm{CSph}=$ $0.021, \mathrm{Sph}=5.500 \times 10^{-4}, \mathrm{~S} 1 \mathrm{P}=0.867 .{ }^{*} p<0.05$ (two-tailed Student's $t$ test). ${ }^{* *} p<0.001$ (two-tailed Student's $t$ test).

man neurons than $\alpha$-synuclein species formed by other experimental lipids.

\section{New long-lived mouse models for GD/PD}

To test the role of altered sphingolipid metabolism in mutant $G B A$-associated PD, we generated new GD mouse lines. Previously produced germline homozygous $G b a \mathrm{KO}$ mice as well as homozygous N370S or L444P mice exhibited disruption of skin permeability barrier that caused neonatal lethality ( $\mathrm{Xu}$ et al., 2003). Therefore, we generated conditional Gba KO mice and Gba mutant knock-in (N370S, L444P) mice, which are rescued by expressing $G b a$ only in skin (Fig. $4 A-C$ ), similar to mice generated by Enquist et al. (2007). The knock-in mice were bred to $G b a$ $\mathrm{KO}$ to generate Gba mutant alleles on a WT and KO background. Significantly, these mice do not die due to skin permeability issues, allowing us to study age-related phenotypes. The homozygous $G b a \mathrm{KO}\left(G b a^{K O / K O}\right)$ and knock-in $\left(G b a^{L 444 P / K O}, G b a^{N 370 S / K O}\right)$ mice are viable, fertile, and grossly normal with the expected body weight at 4 months (Fig. $4 G$ ). The Gba mutant mice recapitulate key pathophysiological features, including enzymatic deficiency of GCase1 (Fig. 4E) and the accumulation of GlcCer and GlcSph (see Figs. 6B, 7B, C,F). Compared with WT mice, there was also a marked decrease of GCase1 protein levels in the brains of mutant GD mice by quantitative Western blotting (Fig. 4D), further validating these lines. Interestingly, we find that the $G b a^{\mathrm{L} 444 \mathrm{P} / \mathrm{KO}}$ line resembles the $G b a^{\mathrm{KO} / \mathrm{KO}}$, whereas the $G b a^{\mathrm{N} 370 \mathrm{~S} / \mathrm{KO}}$ brains have $\sim 50 \%$ GCase1 protein levels (Fig. 4D), a finding supported by previous literature citing N370S as a trafficking mutation (Babajani et al., 2012). Measurement of GCasel enzyme activity in brain homogenates of GD mice revealed that heterozygous $G b a^{\mathrm{KO} / \mathrm{WT}}$, $G b a^{\mathrm{L} 444 \mathrm{P} / \mathrm{WT}}$, and $G b a^{\mathrm{N} 370 \mathrm{~S} / \mathrm{WT}}$ had an intermediate activity level, whereas homozygous $G b a^{\mathrm{KO} / \mathrm{KO}}, G b a^{\mathrm{L} 444 \mathrm{P} / \mathrm{KO}}$, and $G b a^{\mathrm{N} 370 \mathrm{~S} / \mathrm{KO}}$ all lacked GCase1 enzymatic activity (Fig. $4 E$ ).

The Gba mutant mice were crossed to a previously characterized human $\alpha$-synuclein A30P transgenic model of PD $\left(S N C A^{T g}\right)$ to generate homozygous and heterozygous GD/PD mice (Fig. $4 B)$. $S N C A^{T g}$ mice manifest clinical PD symptoms, including resting tremor and progressive motor decline, and show agedependent $\alpha$-synuclein pathology, motor neuron loss, and microglia activation (Fig. 5) (Chandra et al., 2005). Cohorts of homozygous $G b a^{L 444 P / K O} S N C A^{T g}, G b a^{N 370 S / K O} S N C A^{T g}, G b a^{K O / K O}$ $S N C A^{T g}$, and controls (14 genotypes, see Fig. $4 B$ ) were regularly examined for PD phenotypes, pathology, survival, and GD sphingolipid accumulation to determine how GD mutations affected PD manifestation in our models.

\section{GlcSph accumulates early in mutant $G B A$-associated PD}

To evaluate the altered sphingolipid metabolism in the brains of GD/PD mice, we quantified GD associated sphingolipid levels in the brains of a young (3-month) GD/PD mouse cohort by mass spectrometry. We found that GlcSph levels are significantly increased in homozygous $G b a^{L 444 P / K O}, G b a^{N 370 S / K O}$, and $G b a^{K O / K O}$ mice at 3 months of age (Fig. $6 B$ ). We do not observe any change in these values in $S N C A^{T g} \mathrm{PD}$ mice, suggesting that $\alpha$-synuclein transgenic expression does not influence GlcSph levels. Notably, GlcCer, Sph, and S1P levels were not altered at 3 months (Fig. 6A,C,D), even though it has been established that these lipids eventually increase in the plasma of GD patients (Dekker et al., 2011; Mistry et al., 2014). These results are consistent with a previous report indicating that GlcCer does not accumulate in the brain at an early age in a neuropathic GD mouse model; GlcCer was shown to significantly increase only by 6 months of age (Dai et al., 2016), suggesting that accumulation of GlcCer lags behind that of GlcSph in the brain. However, given the high baseline levels of GlcCer relative to other sphingolipids assayed, it is possible that smaller, localized increases are not detectable until levels increase significantly above endogenous levels. To address this possibility, we completed a lysosomal fractionation of mouse brain and found no differences between GlcCer levels in fractions from WT and GD mouse brain enriched for lysosomes (Fig. 6G-K).

Next, we investigated the potency of the observed brain GlcSph concentrations in our in vitro aggregation assay. We determined that incubation with GlcSph at concentrations seen in homozygous GD brains results in the formation of similar oligomeric $\alpha$-synuclein species (Fig. 6E). The effect of GlcSph on $\alpha$-synuclein aggregation was also shown to be concentration dependent by circular dichroism (Fig. 6F). Together, these findings strongly suggest that GlcSph can potently enhance pathological $\alpha$-synuclein aggregation in the brain. 
A Development of Viable Gba KO and Mutant Mice

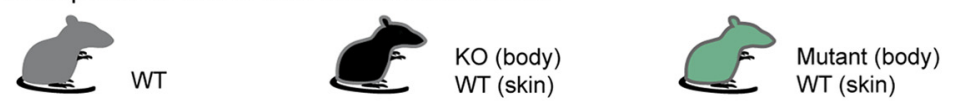

(i) Development of Viable Gba KO Mice:

Gba Neo insert in whole body:

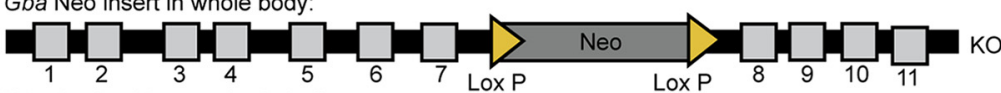

$\mathrm{K} 14-\mathrm{Cre}$ in skin rescuing lethality:

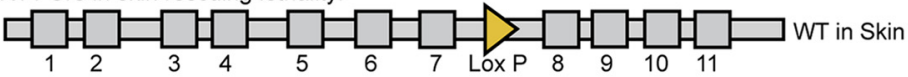

(ii) Development of Viable Gba Mutant Mice:

1 Copy of Gba Neo insert with K14-Cre rescuing lethality:

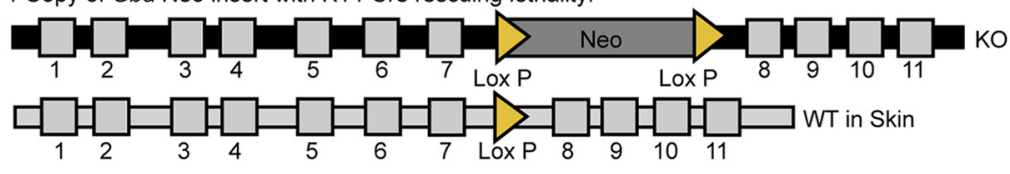

1 Copy of Gba mutantion at exon 9 (N370S) or 10 (L444P):

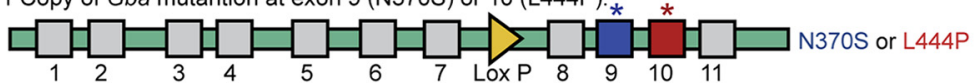

D
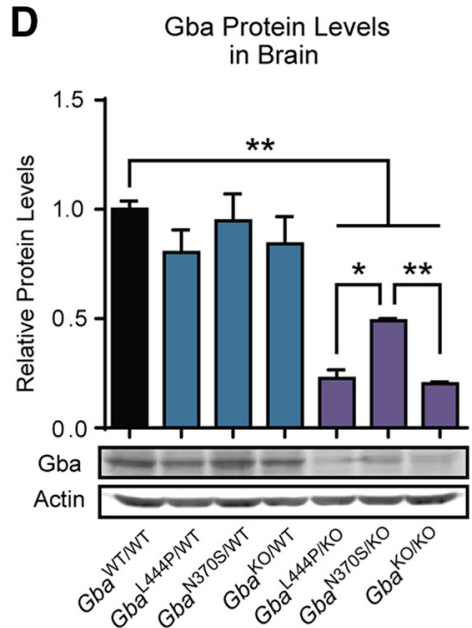

E Gba Activity Levels in Brain

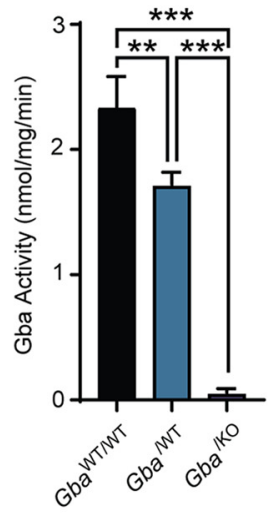

$\mathbf{F}$

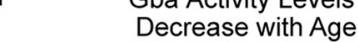

B Summary of Mouse Lines

\begin{tabular}{|c|c|c|c|}
\hline Gba & SNCA & Gba & SNCA \\
\hline WTMT & WT & WTNT & $\mathrm{Tg}$ \\
\hline L444P/WT & WT & L444P/WT & $\mathrm{Tg}$ \\
\hline N370S/WT & WT & N370SNTT & $\mathrm{Tg}$ \\
\hline KO/WT & WT & $\mathrm{KO} / \mathrm{WT}$ & $\mathrm{Tg}$ \\
\hline L444P/KO & WT & L444P/KO & $\mathrm{Tg}$ \\
\hline N370S/KO & WT & $\mathrm{N} 370 \mathrm{~S} / \mathrm{KO}$ & $\mathrm{Tg}$ \\
\hline $\mathrm{KO} / \mathrm{KO}$ & WT & $\mathrm{KO} / \mathrm{KO}$ & $\mathrm{Tg}$ \\
\hline
\end{tabular}

C Genotyping of Gba KO and Mutant Mice

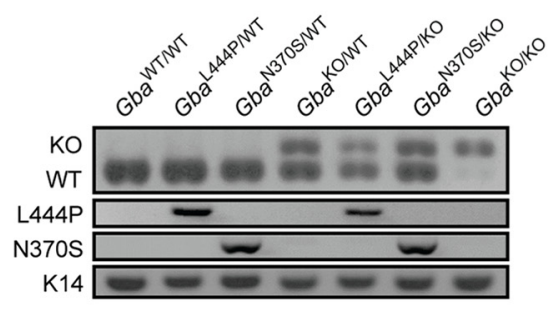

G

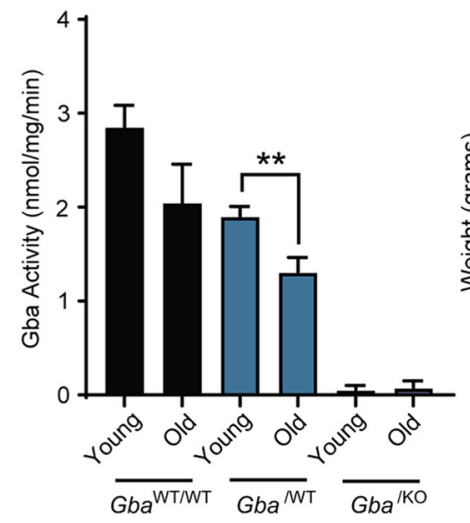

Weight of Male Gba Mice at 4 Months

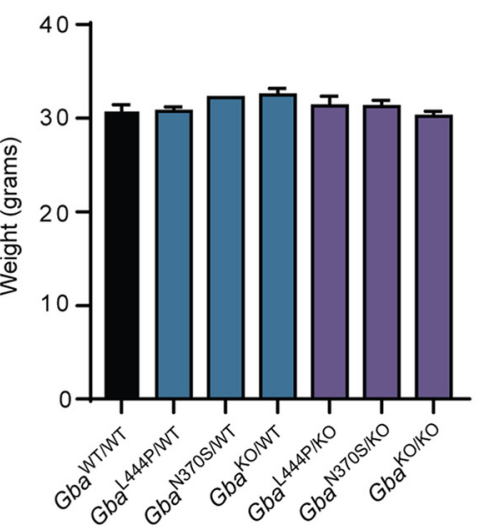

Figure 4. Generation and characterization of GD/PD mice. A, Schematic depicting design of Gba KO and mutant mouse lines: gray represents WT; black represents K0; green represents mutant. Ai, Homozygous Gba KO mice were produced through insertion of a Neo cassette between exons 7 and 8. Gba KO was rescued in skin using Cre recombinase, preventing lethality in these lines. Aii, Viable Gba mutant mice ( $G b a^{\mathrm{N} 3705 / K 0}$ and $G b a^{\mathrm{L} 444 \mathrm{P} / \mathrm{KO}}$ ) were generated with one copy of Gba N370S or L444P and one copy of Gba K0 with a rescue in skin, as noted above, to create "homozygous" mutants. B, Summary of all 14 genotypes assessed. C, Positive PCR-based genotyping of all $7 \mathrm{GD}$ mouse lines. $\boldsymbol{D}$, Quantitative Western blotting of GCase 1 protein levels in brains of GD/PD mice. $N=$ 2 experiments. $p$ values versus WT: $\mathrm{L} 444 \mathrm{P} / \mathrm{WT}=0.127, \mathrm{~N} 370 \mathrm{~S} / \mathrm{WT}=0.626, \mathrm{KO} / \mathrm{WT}=0.230, \mathrm{~L} 444 \mathrm{P} / \mathrm{KO}=0.002, \mathrm{N370 \textrm {S }} / \mathrm{KO}=0.003, \mathrm{KO} / \mathrm{KO}=0.001$. $p$ values versus N370S/KO: $\mathrm{L} 444 \mathrm{P} / \mathrm{KO}=$

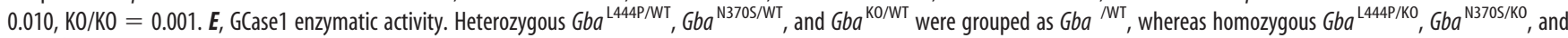

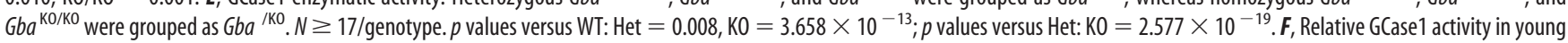
(3-months) and old (12-months) brains. $N \geq 6$ per genotype. $p$ values versus corresponding young cohort:WT $=0.170$, Het $=0.003, K 0=0.753$. G, GD mice are viable and exhibit normal weights at 4 months of age. $\boldsymbol{D}-\boldsymbol{F},{ }^{*} p<0.05$ (two-tailed Student's $t$ test). ${ }^{* *} p<0.01$ (two-tailed Student's $t$ test). ${ }^{* * *} p<0.001$ (two-tailed Student's $t$ test).

GD/PD mouse mortality correlates with level of sphingolipid accumulation in brain

Survival of GD/PD mice was assessed over the course of 24 months. Only mice suffering from end-stage motor phenotypes associated with $\mathrm{PD}$ or those that were found dead were included in this analysis. The ages at death of $S N C A^{T g}$, heterozygous $G b a^{\prime W T} S N C A^{T g}$, and homozygous $G b a^{/ K O} S N C A^{T g}$ mice were collected and plotted as frequency distributions (Fig. 7A). A Gaussian curve was fitted to the $S N C A^{T g}$ distribution, indicating values within 1,2, and 3 SDs of the mean age of death (16.2 months). This curve was overlaid onto the frequency distributions for heterozygous $G b a^{\prime W T} S N C A^{T g}$ and homozygous $G b a^{/ K O} S N C A^{T g}$ mice, allowing for visual comparison between genotypes (Fig. 7A).

Although all values of the $S N C A^{T g}$ line fall within 2 SDs of the $S N C A^{T g}$ mean, a small fraction of heterozygous $G b a^{\prime W T} S N C A^{T g}$ and a larger fraction of homozygous $G b a^{/ K O} S N C A^{T g}$ values fall farther than $2 \mathrm{SDs}$ to the left of the $S N C A^{T g}$ mean (Fig. 7A). These data show that a subset of the GD/PD mice exhibit premature morbidity relative to the anticipated age of death of $S N C A^{T g}$ mice, suggesting an acceleration of PD phenotypes and pathology due to contributions from $G b a$ mutation. This distribution mirrors the patient population, in which GBA mutation confers a risk for PD onset in a dose-dependent manner. Our GD/PD mouse lines also capture the imperfect penetrance of the GBA phenotypes to PD manifestation in humans. As a means of investigating the molecular differences between the early death and anticipated death groups, we immunostained brain sections from age-matched homozygous $G b a^{\prime K O} S N C A^{T g}$ early death mice and homozygous $G b a^{/ K O} S N C A^{T g}$ anticipated death mice, using an antibody against GlcCer (Fig. 7B) (Doering et al., 2002; D’Angelo et al., 2007). We discovered an approximately fivefold increase in GlcCer levels in the early death group relative to the anticipated 
A Motor Neuron Loss in SNCA ${ }^{\mathrm{Tg}}$ Mice

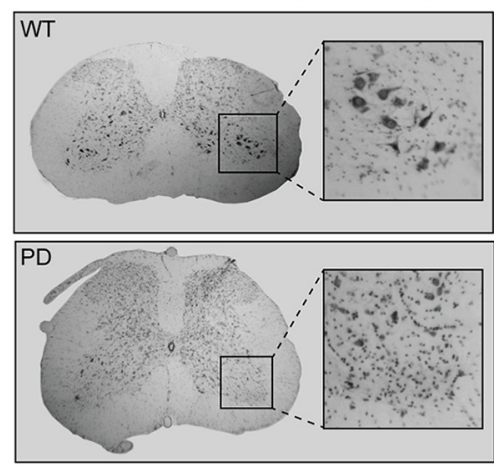

E

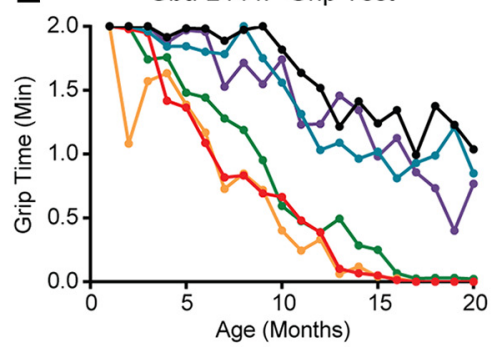

G

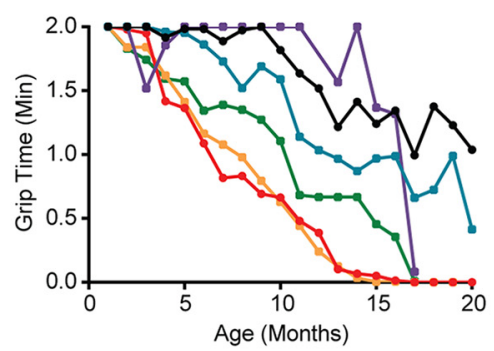

B Lumbar Motor Neurons

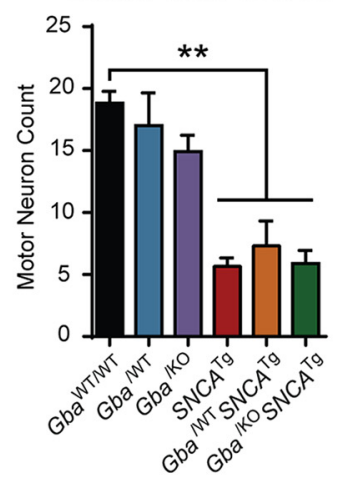

$\rightarrow$ Gba $a^{\text {WTNT }}(11)$

$\rightarrow$ Gba ${ }^{\mathrm{L} 44 \mathrm{P} / \mathrm{NT}}(8)$

$\rightarrow G b a^{\mathrm{L} 444 \mathrm{P} / K O}(6)$

$\rightarrow$ Gba ${ }^{\text {WTMT }} S N C A^{T g}(17)$

$\rightarrow G b a^{\text {L444PNTT }} S N C A^{T g}(5)$

$\rightarrow G b a^{L 444 P / K O} S N C A^{T g}(8)$

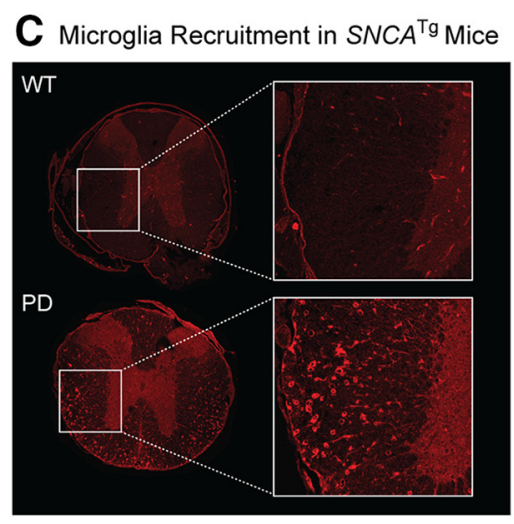

C Microglia Recruitment in SNCA ${ }^{\top \mathrm{g}}$ Mice

F

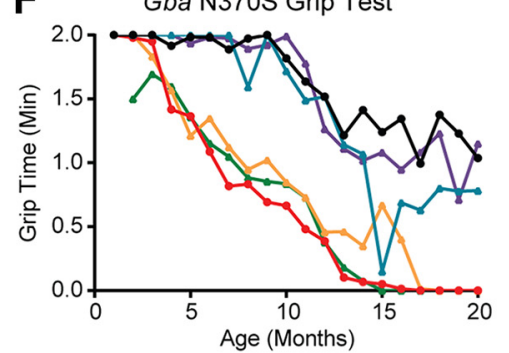

H

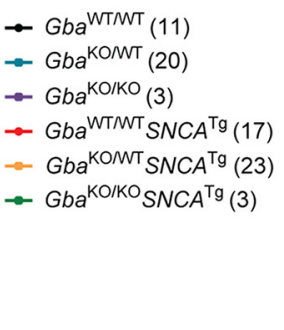

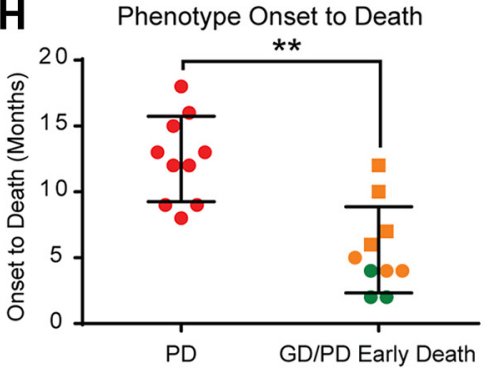

D Microglia Levels

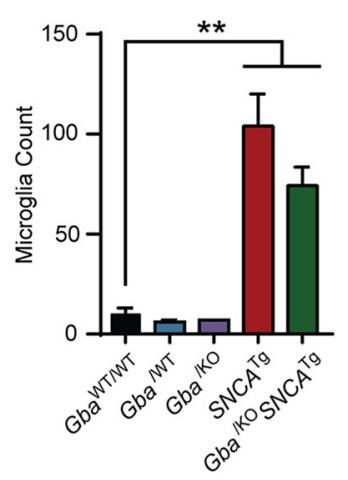

$\rightarrow G b a^{\text {WT/NT }}(11)$

- Gba ${ }^{\mathrm{N} 370 \mathrm{~S} / \mathrm{NT}}$ (4)

- $G b a^{\mathrm{N} 370 \mathrm{~S} / \mathrm{KO}}(6)$

$\rightarrow G b a^{\mathrm{WT} / N \mathrm{~T}} S N C A^{\mathrm{Tg}}(17)$

- Gba ${ }^{\mathrm{N} 370 S N^{\top}} S N C A^{\mathrm{Tg}}(5)$

$\rightarrow G b a^{\mathrm{N} 370 \mathrm{~S} / \mathrm{KO}} S N C A^{\top \mathrm{Tg}}(9)$

Figure 5. Characterization of GD/PD mice. $A$, Representative images of motor neurons in the ventral horn of $L 3$ spinal cords. All PD lines showed loss of motor neurons in the lumbar spinal cord, consistent with previous literature (Chandra et al., 2005). B, Quantification of motor neuron loss in Gba ${ }^{\text {WT/WT }}$, heterozygous Gba ${ }^{\text {WT }}$, and homozygous Gba ${ }^{\text {/KO }}$ with and without SNCA ${ }^{\text {Tg }}$.

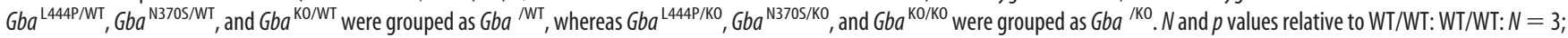
/WT: $N=2, p=0.489 ; / K 0: N=5, p=0.144 ;$ SNCA $^{\mathrm{Tg}}: N=2, p=0.002 ; /$ WT SNCA ${ }^{\mathrm{Tg}}: N=2, p=0.009 ; / K_{0}$ SNCA $^{\mathrm{Tg}}: N=3, p=0.001$. C, Representative images of microglial staining in T10

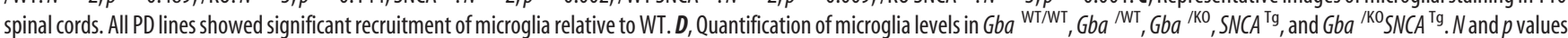
relative to WT/WT: WT/WT: $N=5 ; / \mathrm{WT}: N=2, p=0.315 ; / K 0: N=1$, no $p$ value; $\mathrm{SNCA}^{\mathrm{Tg}}: N=2, p=0.005 ; / K 0 \mathrm{SNCA}^{\mathrm{Tg}}: N=3, p=0.001 . \boldsymbol{B}, \boldsymbol{D}$, ${ }^{* *} p<0.01$, relative to Gba ${ }^{\text {WT/WT }}$ (two-tailed Student's t test). Hanging grip test was used as an indicator of declining motor function in $(\boldsymbol{E})$ Gba L444P, $(\boldsymbol{F})$ Gba N370S, and (G) Gba K0 lines. All PD lines exhibit motor deficits by 10 months. Both sexes were used; $N$ is noted in parentheses after each genotype. $\boldsymbol{H}$, Graph of months elapsed between onset of motor phenotype measured by the hanging grip test and death. GD/PD mice dying earlier than 14 months (GD/PD Early Death) show accelerated decline in motor function relative to PD mice. $p$ value relative to PD $=1.64 \times 10^{-4}$. ${ }^{* *} p<0.001$ (two-tailed Student's $t$ test).

death group (Fig. 7B), strongly correlating PD-related morbidity to increased GD sphingolipid levels in brain.

These results indicate that the accumulation of GD-related sphingolipids in the brain may be an important factor in prompting the early death observed in homozygous $G b a^{/ K O} S N C A^{T g}$ mice. Interestingly, we noticed that only homozygous $G b a^{L 444 P / K O}$ $S N C A^{T g}$ and $G b a^{K O / K O} S N C A^{T g}$, and not $G b a^{N 370 S / K O} S N C A^{T g}$, contributed to the early death group. These findings suggest that morbidity may be inversely correlated to $G b a$ protein level in brain, as homozygous $G b a^{N 370 S / K O} S N C A^{T g}$ were previously found to have $\sim 50 \%$ residual protein levels (Fig. $4 D$ ). This finding is consistent with clinical data that the N370S mutation has a lower odds ratio for PD than L444P (Gan-Or et al., 2008).

Aged GD/PD mice exhibit $\alpha$-synuclein pathology in regions of GlcCer accumulation Using the early death homozygous $G b a^{/ K O} S N C A^{T g}$ mice and WT, $S N C A^{T g}$, and $G b a^{/ \mathrm{WT}} S N C A^{T g}$ controls, we further investigated relative levels of GlcCer and $\alpha$-synuclein pathology in brain. As noted in our comparative studies of early and anticipated death staining, multiple brain regions showed increased GlcCer levels in homozygous early death mice (Fig. 7C,F). Together with our lipidomic analyses, these data support an age-dependent accumulation of GlcCer in the brain. Here we show representative images of GlcCer staining in the CA3 region in hippocampus. Quantitative immunofluorescence showed that homozygous $G b a^{L 444 P / K O} S N C A^{T g}$ and $G b a^{K O / K O} S N C A^{T g}$ mice have $\sim 10$-fold GlcCer accumulation relative to WT levels $(9.8 \pm 2.99$ vs $1.2 \pm$ $0.11 ; p=0.0096)$.

We and others have shown that $S N C A^{T g} \mathrm{PD}$ mice exhibit $\alpha$-synuclein pathology, which is associated with increased insolubility of the protein (Chandra et al., 2005; Gallardo et al., 2008). To monitor $\alpha$-synuclein pathology, we coimmunostained the above cohort of GD/PD brain sections with an antibody against Ser 129 phosphorylated $\alpha$-synuclein, a marker of $\alpha$-synuclein pathology (Saito et al., 2003). As expected, $S N C A^{T g}$ PD mice show 
A

Brain GlcCer Levels

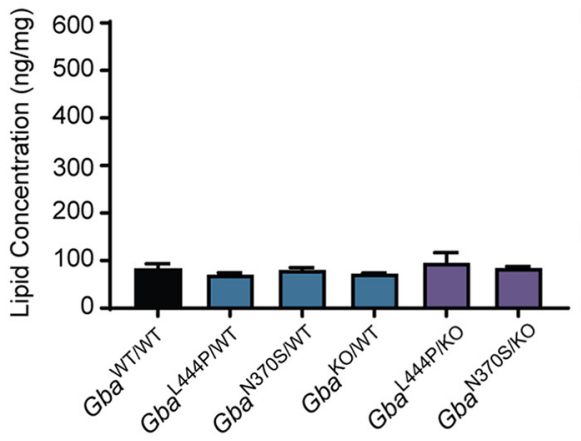

C

Brain Sph Levels

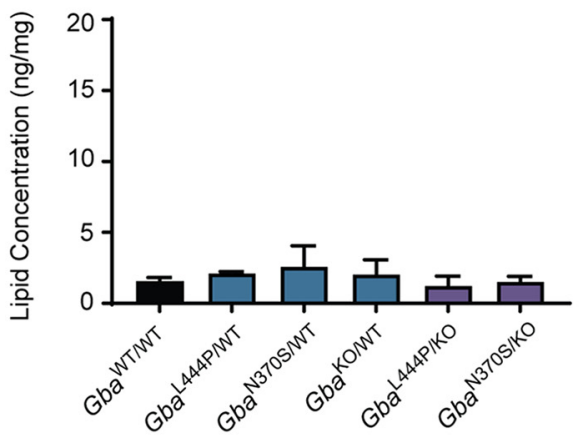

B

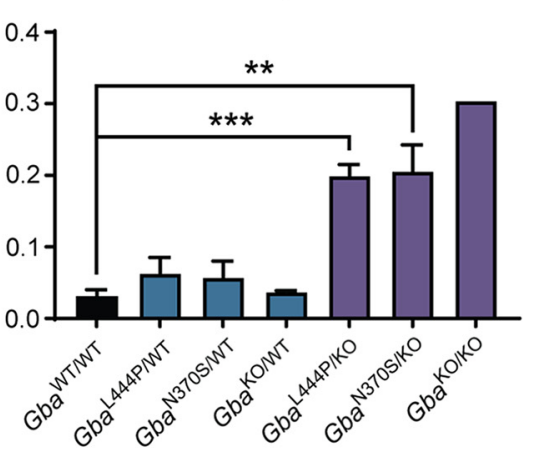

D

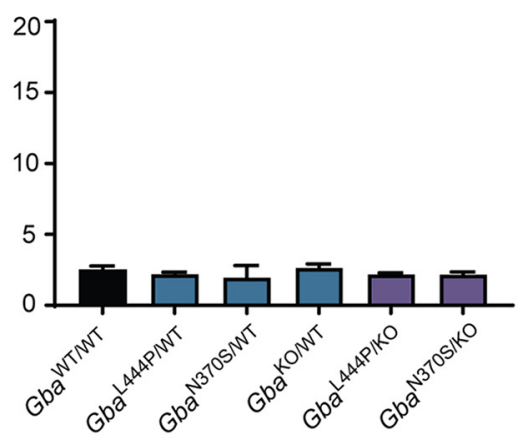

E Aggregated a-Synuclein Induced by Physiological Levels of GlcSph

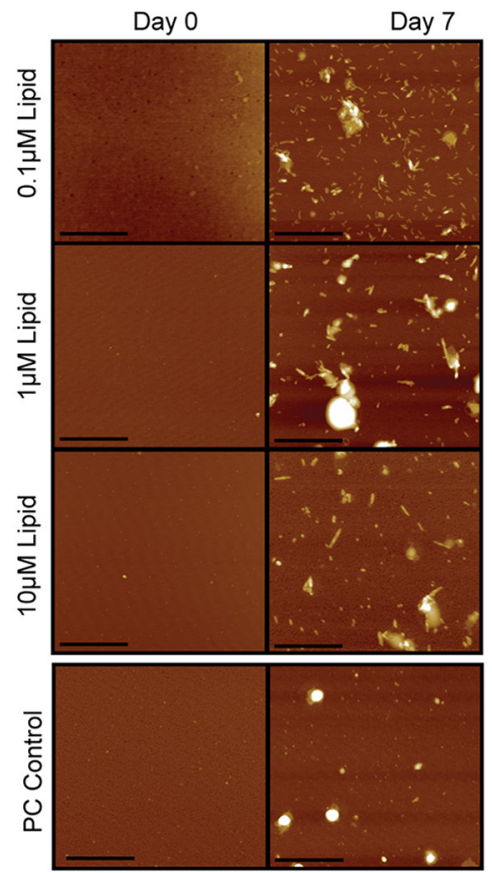

F GlcSph Derived $\beta$-Sheeted $\alpha$-Synuclein (Day 0 and 7)

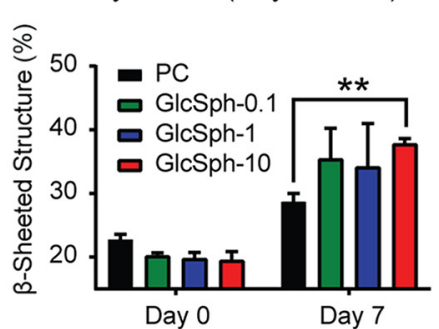

I Concentration of Lysosome Fractions

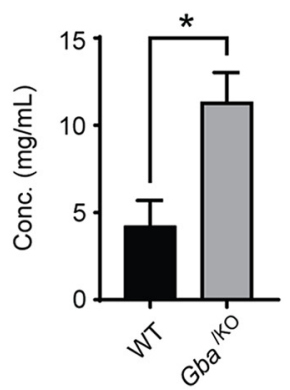

G Brain Fractionation for Lysosomal Enrichment Bands Post-Fractionation:

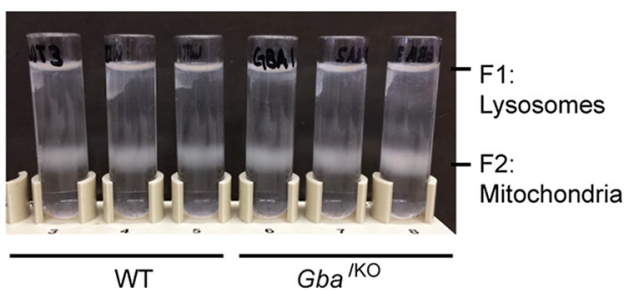

H Lysosomal Enrichment Confirmation

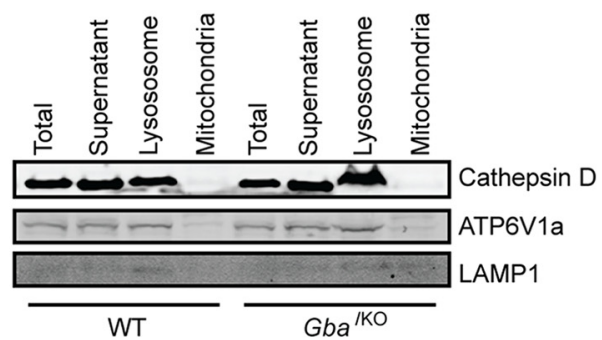

$\mathbf{J}$

GlcCer Standards for Dot Blot

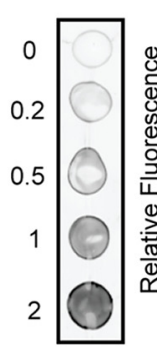

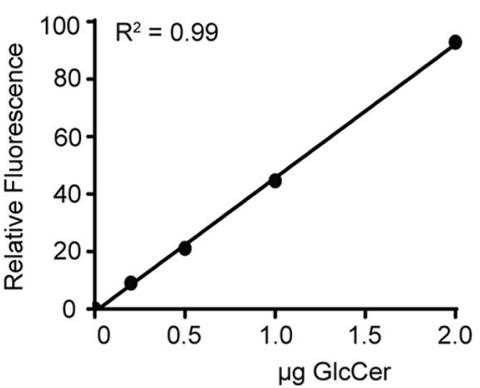

K GlcCer Levels in Lysosomal Fractionation

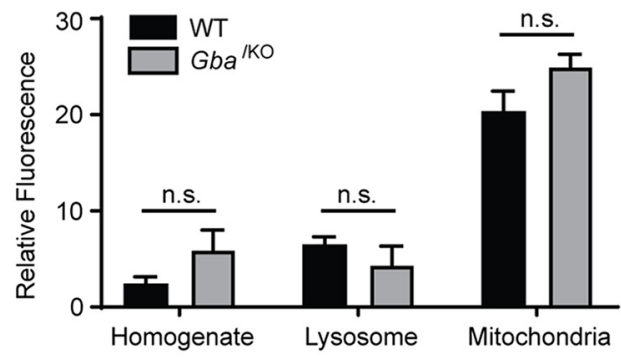

Figure 6. Gl GSph accumulates early in mouse brain: $A, G \mid C C e r ; B, G l C S p h ; C, S p h ; D, S 1 P$ levels in GD/PD brains. $N=2-6$ per genotypes, except $G b a^{\text {Ko/k0 }}(N=1)$; age of mice $=2-3$ months. $p$ value relative to WT/WT for GlCSphlevels: L444P/WT $=0.234$, N370S/WT $=0.313$, KO/WT $=0.608$, L444P/KO $=3.350 \times 10^{-4}{ }^{,}$N370S/KO $=0.002 .{ }^{*} p<0.05 .{ }^{* *} p<0.01$. ${ }^{* * *} p<0.001 . E$, AFM images of $\alpha$-synuclein incubated with $0.1,1$, and $10 \mu \mathrm{M} \mathrm{GlSSph} \mathrm{with} \mathrm{PC} \mathrm{control} \mathrm{on} \mathrm{day} 0$ and 7 .Scale bars, $1 \mu \mathrm{m}$. F, Percentage $\beta$-sheeted content of $\alpha$-synuclein in the presence of $0.1,1$, and $10 \mu \mathrm{m} \mathrm{Gl}$.Sph on day 0 and day $7 . N=$ 3 for all samples. $p$ value relative to PC: GlSph-0.1 $=0.243$, Gl SSph-1 $=0.472$, Gl SSph-10 $=0.004$. ${ }^{* *} p<0.01$ (two-tailed Student's test). G, Subcellular fractionation showing lysosomes on the top fraction (F1) and mitochondria on the bottom fraction between $27 \%$ and $23 \%$ density interfaces (F2). Two smaller bands are seen between F1 and F2 (not taken). $\boldsymbol{H}$, Western blot shows enrichment of lysosomes in F1. Cathepsin D, ATP6V1a, and LAMP1 were used as lysosomal markers; Cathepsin D and ATP6V1a can be seen in the homogenate, supernatant, and lysosomal fraction, but not in the mitochondrial fraction. LAMP1 can be seen predominantly in thelysosomal fraction. I, Relative protein levels in lysosomal fractions were determined by BCA. GBA KOlysosomes (11.38 $\mathrm{mg} / \mathrm{ml}$ ) werefound to have almost 3 times as much protein as WT lysosomes $(4.27 \mathrm{mg} / \mathrm{ml})$, a likely indicator of expected lysosomal enlargement and dysfunction in the GBA KO mice. $p$ value $/ K 0$ relative to WT $=0.031$. ${ }^{*} p<0.05$ (two-tailed Student's $t$ test).J, Dot blot shows relative GIcCer levels using a GlcCer antibody (Glycobiotech). Blotted GIcCer lipid shows that the dot blotmethod is robust and quantitative, with a standard curve with $R^{2}=0.99 . K_{1}$, GlcCer levels from brain homogenate, lysosomal fraction, and mitochondrial fraction were analyzed using the dot blot method in J. No difference between WT and GBA KO was found in any of the fractions, including total brain homogenates confirming the lipidomic results in $\boldsymbol{A}$. However, there was a clear enrichment of GlcCer in the mitochondrial fraction relative to the others. 
A

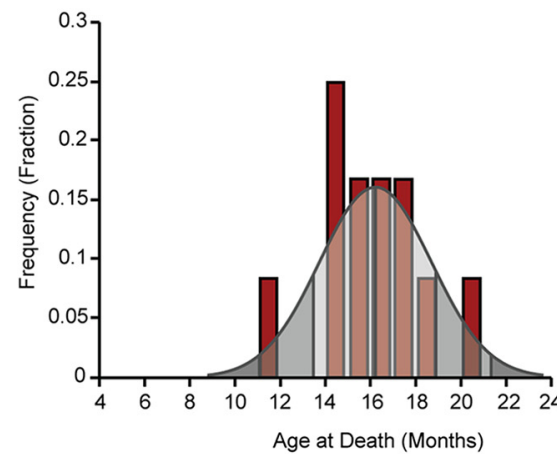

Age at Death (Months)
Heterozygous GD/PD Mice: Age at Death Homozygous GD/PD Mice: Age at Death

Homozygous

15- GD/PD Brain
C
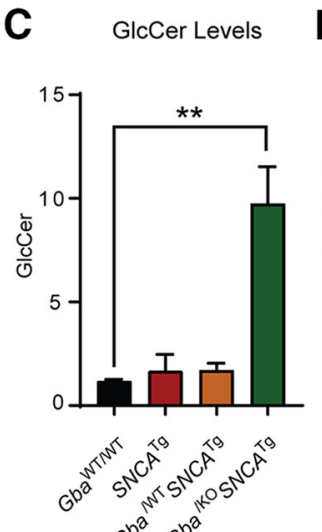

$\mathrm{C}^{2} \mathrm{O}^{2}$
D Phosphorylated a-Synuclein S129

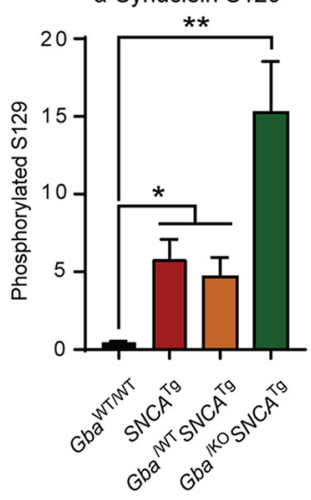

E Correlation between GlcCer Levels and Phosphorylated a-Synuclein S129

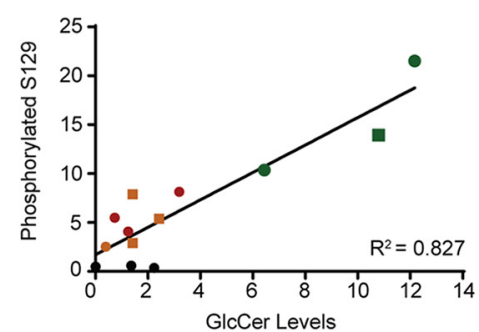

-WT $\mathrm{Gba}^{\mathrm{KONNT}} \mathrm{SNCA}{ }^{\mathrm{Tg}} \quad \mathrm{Gba}^{\mathrm{KO} / K O} \mathrm{SNCA}^{\mathrm{Tg}}$ - $\mathrm{SNCA}^{T g} \bullet \mathrm{Gba}^{\mathrm{L} 444 \mathrm{PN} N} \mathrm{SNCA}^{\mathrm{Tg}} \bullet \mathrm{Gba}^{\mathrm{L} 444 \mathrm{P} / K O} \mathrm{SNCA}^{T g}$

F GlcCer Levels and Phosphorylated a-Synuclein in CA3 Region of Hippocampus
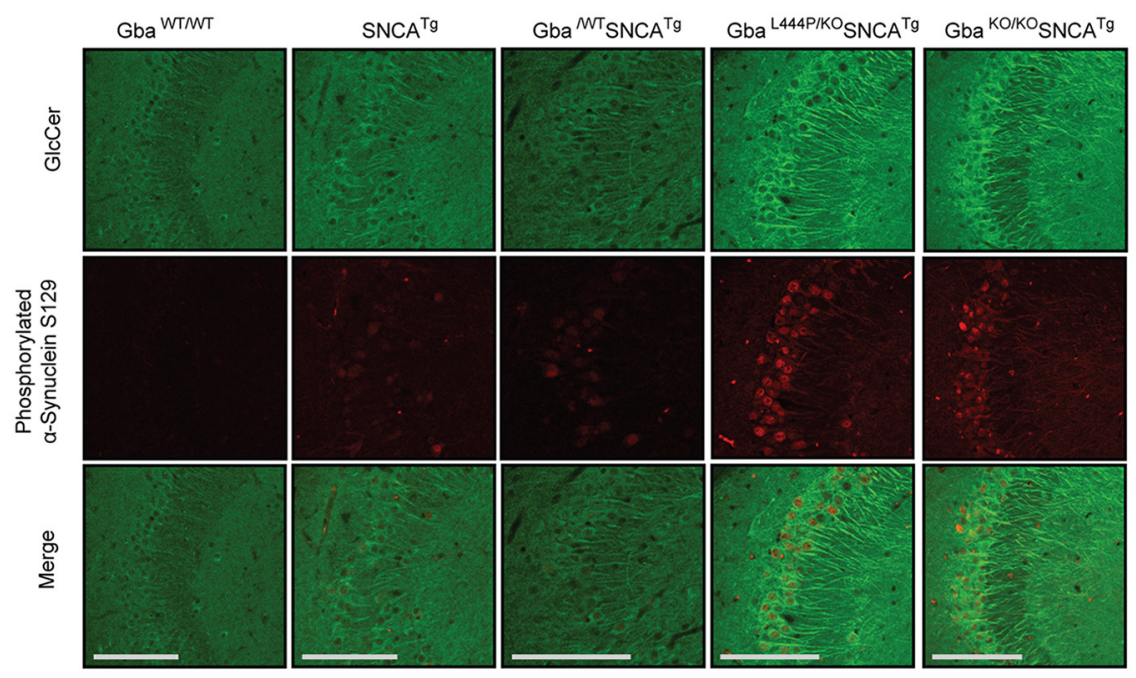

G Phosphorylated a-Synuclein S129:

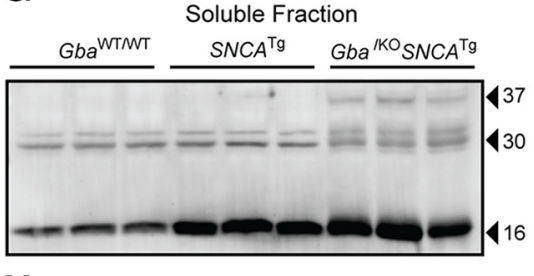

H Phosphorylated a-Synuclein $\mathrm{S} 129$ $(16 \mathrm{kDa})$

Phosphorylated a-Synuclein $\mathbf{S 1 2 9}$
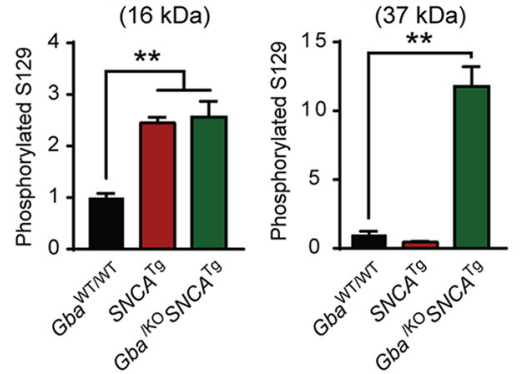

| Soluble Oligomer Levels

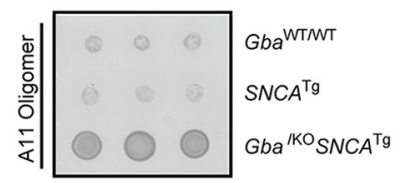

\section{J Aggregated a-Synuclein} Levels by ELISA

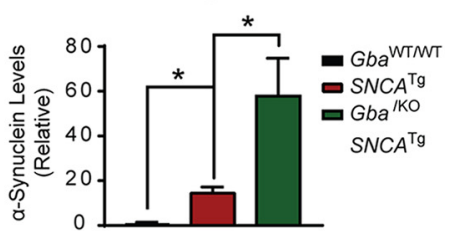

Figure 7. GD/PD mice exhibit $\alpha$-synuclein pathology and GlcCer accumulation. $A$, Histograms of age of death of SNCA ${ }^{\text {Tg }}$ mice $(N=12)$, heterozygous Gba ${ }^{\text {WT }}$ SNCA ${ }^{\text {Tg }}(N=36)$, and homozygous $\mathrm{Gba}^{/ \mathrm{KO}} \mathrm{SNCA}{ }^{\mathrm{Tg}}(N=18)$. Gaussian curve fitted to SNCA ${ }^{\mathrm{Tg}}$ histogram superimposed over all three histograms, showing differences in distributions; 1 , 2, and $3 \mathrm{SD}$ s from the mean shown through progressively darker shading under Gaussian curve. $B$, Quantification of GlcCer levels in the CA3 region of hippocampus in homozygous $G b a^{/ K 0} S N C A{ }^{\mathrm{Tg}}$ brain of early death and anticipated death mice ( $N=3$ mice per group). $N$ and $p$ values relative to anticipated death: anticipated death: $N=3$; early death: $N=3, p=0.013$. C, Quantification of GlcCer levels in the CA3 region of hippocampus in GD/PD mice cohorts. Values normalized

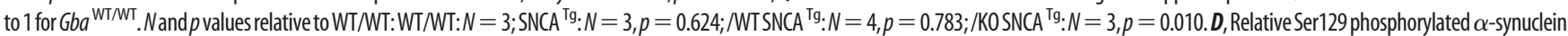
levels in the CA3 region of the hippocampus in the same brains. $N$ and $p$ values relative to WT/WT:WT/WT: $N=3 ; \mathrm{SNCA}^{\mathrm{Tg}}: N=3, p=0.010 ; / \mathrm{WT} \mathrm{SNCA}^{\mathrm{Tg}}: N=4, p=0.036 ; / K 0$ SNCA ${ }^{\mathrm{Tg}}: N=3, p=0.010$. $\boldsymbol{E}$, Correlation of GICCer and Ser129 phosphorylation $\alpha$-synuclein levels across the different genotypes. $r^{2}=0.827$, Pearson's product moment-correlation $p=1.618 \times 10^{-5}$. $N=3$ or 4 per genotype; age of mice $=8-11$ months. $\boldsymbol{F}$, Representative brain sections stained with antibodies to GlcCer and Ser129 phosphorylated $\alpha$-synuclein. Scale bar, $250 \mu$ m. $\mathbf{G}$, Western blot of soluble fraction of mouse brain homogenate following differential detergent extract in age-matched Gba ${ }^{\text {WT/WT }},{ }^{2} N C A^{\mathrm{Tg}}$, and Gba ${ }^{/ K 0} S_{N C A}{ }^{\mathrm{Tg}}$ exhibiting early death, probing for phosphorylated $\alpha$-synuclein S129. $\boldsymbol{H}$, Quantification of $\boldsymbol{G}$, focusing on expected bands at 16 and $37 \mathrm{kDa}$. $16 \mathrm{kDa}: N$ and $p$ values versus WT/WT: SNCA ${ }^{\mathrm{Tg}}: N=3, p=4.120 \times 10^{-4} ; / \mathrm{KO} \mathrm{SNCA}{ }^{\mathrm{Tg}}: N=3, p=0.008 .37 \mathrm{kDa}: N$ and $p$ values versus WT/WT:SNCA ${ }^{\mathrm{Tg}}: N=$

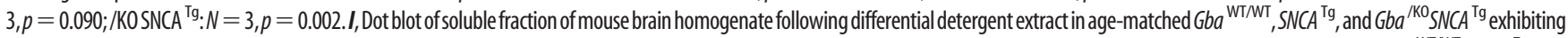
early death, using anti-oligomer antibody A11. J, Quantification of ELISA assay probing for the presence of aggregated $\alpha$-Synuclein in total brain homogenate from age-matched Gba ${ }^{\text {WT } / W T}$, SNCA ${ }^{\text {Tg }}$, and

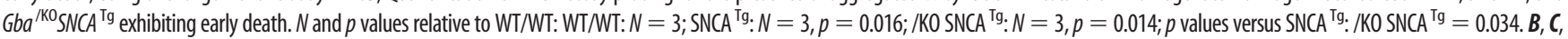
Two-tailed Student's t test. $\boldsymbol{D}, \boldsymbol{H}, \mathbf{J}, 0$ ne-tailed Student's $t$ test. ${ }^{*} p<0.05 .{ }^{* *} p<0.01$. 
A Gba2 Activity Levels in Mouse Brain
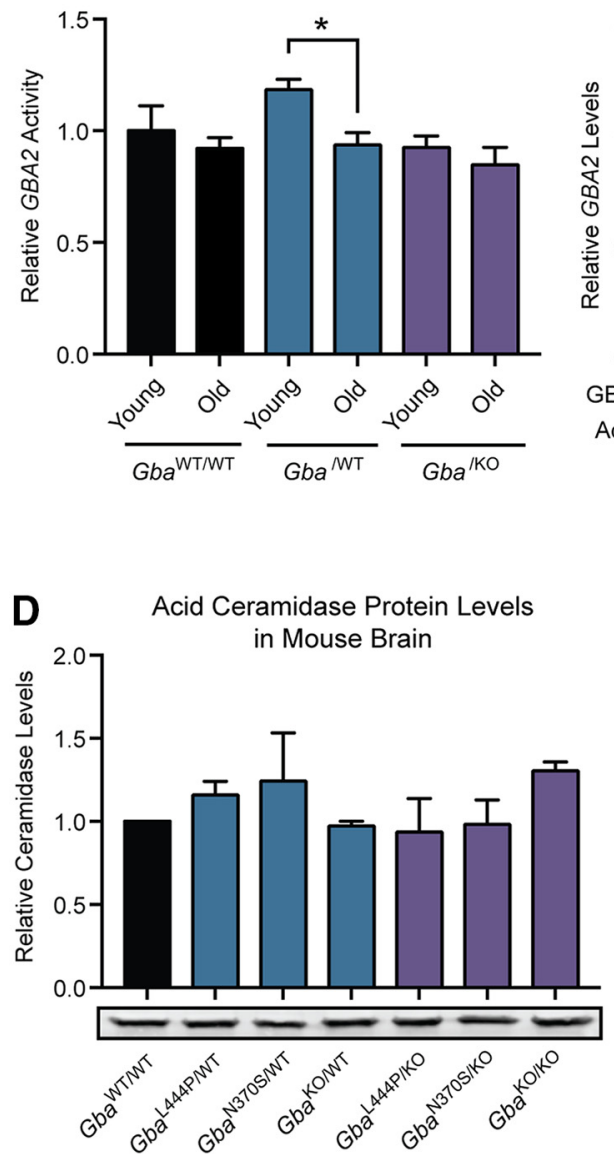

B
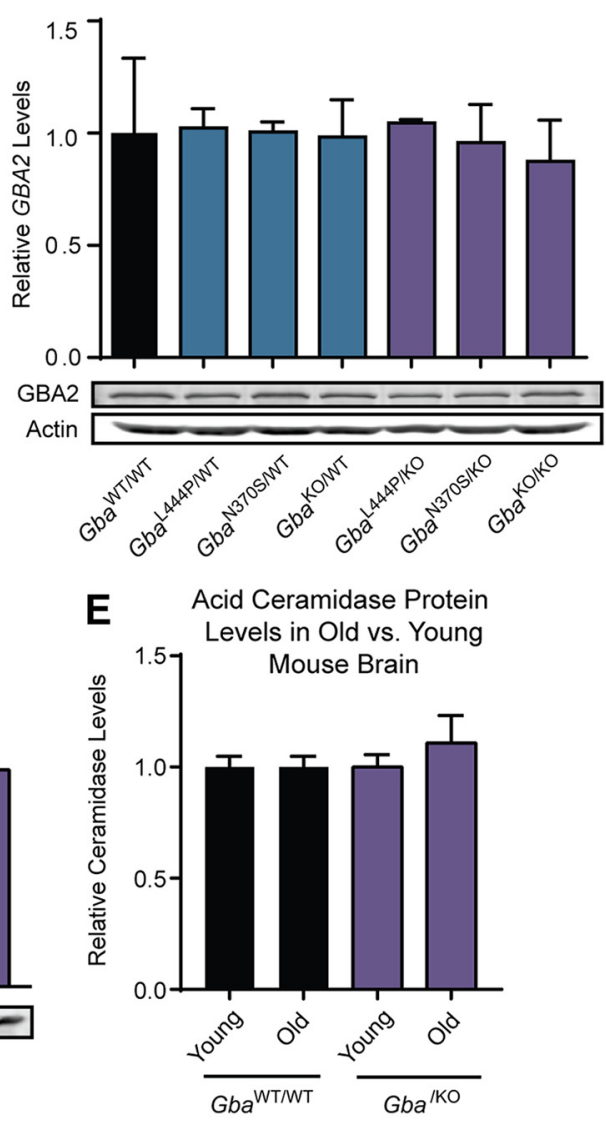

C
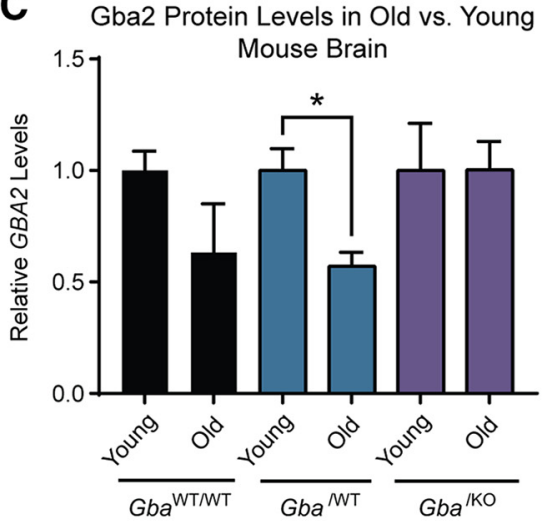

Figure 8. GBA2 and acid ceramidase levels in GD mice. $A$, Gba2 activity levels relative to Gba ${ }^{\mathrm{WT} / \mathrm{WT}}$. Heterozygous Gba $a^{\mathrm{L44P} / \mathrm{WT}}$, Gba ${ }^{\mathrm{N} 3705 / \mathrm{WT}}$, and Gba ${ }^{\mathrm{KO} / \mathrm{WT}}$ were grouped as Gba ${ }^{\text {WWT }}$, whereas homozygous $G b a^{\mathrm{L} 444 \mathrm{P} / \mathrm{KO} 0}, G b a^{\mathrm{N} 3705 / \mathrm{KO}}$, and $\mathrm{Gba}{ }^{\mathrm{KO} / \mathrm{KO} 0}$ were grouped as $\mathrm{Gba} / \mathrm{Ko}$. Activity is shown for both young (3-month) and old (12-month) mice. Nand $p$ values relative to young cohort: WT/WT: $N=83$-month, 91-year mice, $p=0.507 ; /$ WT: $N=263$-month, 91-year mice, $p=0.038 ; / K 0: N=163$-month, 81-year mice, $p=0.398 .{ }^{*} p<0.05$ (two-tailed Student's ttest). $\boldsymbol{B}$, Gba2 protein

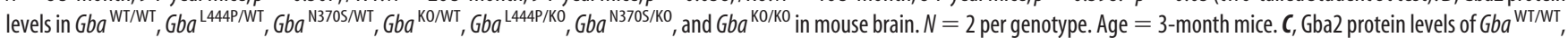
$\mathrm{Gba}^{\mathrm{WWT}}$, and $\mathrm{Gba}{ }^{/ \mathrm{KO} 0}$. Protein levels are shown for both young (3-month) and old (12-month) mice. $N=3$ per genotype. $p$ values relative to young cohort: WT/WT $=0.193, / \mathrm{WT}=0.021, / K 0=$ 0.991. ${ }^{*} p<0.05$ (two-tailed Student's $t$ test). $\boldsymbol{D}$, Acid ceramidase levels normalized to actin shown for all GD genotypes, determined via Western blot. $N=2$ per genotype. Age $=3$-month-old mice. $E$, Acid ceramidase levels of $G b a^{\mathrm{WT} / W T}, G b a^{/ \mathrm{WT}}$, and $G b a^{/ \mathrm{KO} 0}$. Protein levels are shown for both young (3-month) and old (12-month) mice. $N=3$ per genotype.

increased Ser129 phosphorylated $\alpha$-synuclein levels in the brain, but homozygous $G b a^{L 444 P / K O} S N C A^{T g}$ and $G b a^{K O / K O} S N C A^{T g}$ mice developing early phenotypes show even larger increases (Fig. $7 D, F$ ). To determine the relationship between GlcCer and Ser129 phosphorylated $\alpha$-synuclein levels, we measured and compared relative intensities. As seen in Figure $7 E$, GlcCer and Ser 129 phosphorylated $\alpha$-synuclein levels are linearly correlated $\left(r^{2}=0.82\right.$, Pearson's product moment-correlation $p=$ $\left.1.618 \times 10^{-5}\right)$. To confirm this finding, we determined the average Mander's coefficient M2 expressing overlap between the two channels as 0.841 , suggesting that GlcCer accumulation, and likely the other GD sphingolipids, are triggers for $\alpha$-synuclein Ser129 phosphorylated pathology. We further confirmed the presence $\alpha$-synuclein pathology in homozygous, phenotypic $G b a^{L 444 P / K O} S N C A^{T g}$ and $G b a^{K O / K O} S N C A^{T g}$ mouse brain using Western blotting, showing the appearance of a soluble oligomeric $\alpha$-synuclein species in $G b a^{L 444 P / K O} S N C A^{T g}$ and $G b a^{K O / K O}$. $S N C A^{T g}$ mice, which was not present in $S N C A^{T g}$ mouse brain (Fig. 7G,H). These results were verified using dot blot with an anti-oligomer antibody and a commercial ELISA kit against oligomeric and aggregated $\alpha$-synuclein (Fig. $7 I, J$ ).

Finally, we examined the two key enzymes that regulate GlcSph levels: acid ceramidase and Gba2. Quantitative Western blotting showed that neither acid ceramidase nor Gba2 levels change with Gba genotype (Fig. 8B,D). When we examined these two enzymes in aged mice, we observed that, whereas acid ceramidase levels were unaltered, both Gba2 activity and protein levels decreased with age (Fig. $8 A, C, E$ ). Decreasing Gba2 is likely to contribute to the further accumulation of GlcSph in an agedependent manner in our mouse lines and is consistent with clinical data (Ferraz et al., 2016).

\section{Discussion}

Although it is firmly established that GBA mutations, even in the heterozygote carrier state, are a major genetic risk factor for PD, the molecular mechanism(s) underlying the association of $G B A$ mutations and PD are poorly understood. Hitherto, the focus in the field has been on GD mutant GCase1 itself and its interactions with $\alpha$-synuclein, focusing mainly on gain-of-function mechanisms, or lysosomal dysfunction to describe the nexus between GBA mutations and PD. These studies are hard to reconcile with the subcellular localization of GCase1 (lysosomal) and $\alpha$-synuclein (presynaptic), and do not explain the striking incremental risk of PD associated with null or severe GBA alleles (i.e., $84 \mathrm{G}$ ins $G$ mutation, which leads to frame shift and premature protein truncation) compared with mild mutations (N370S) (Gan-Or et 
Effects of Gaucher Sphingolipid Lipid Accumulation on a-Synuclein Pathology

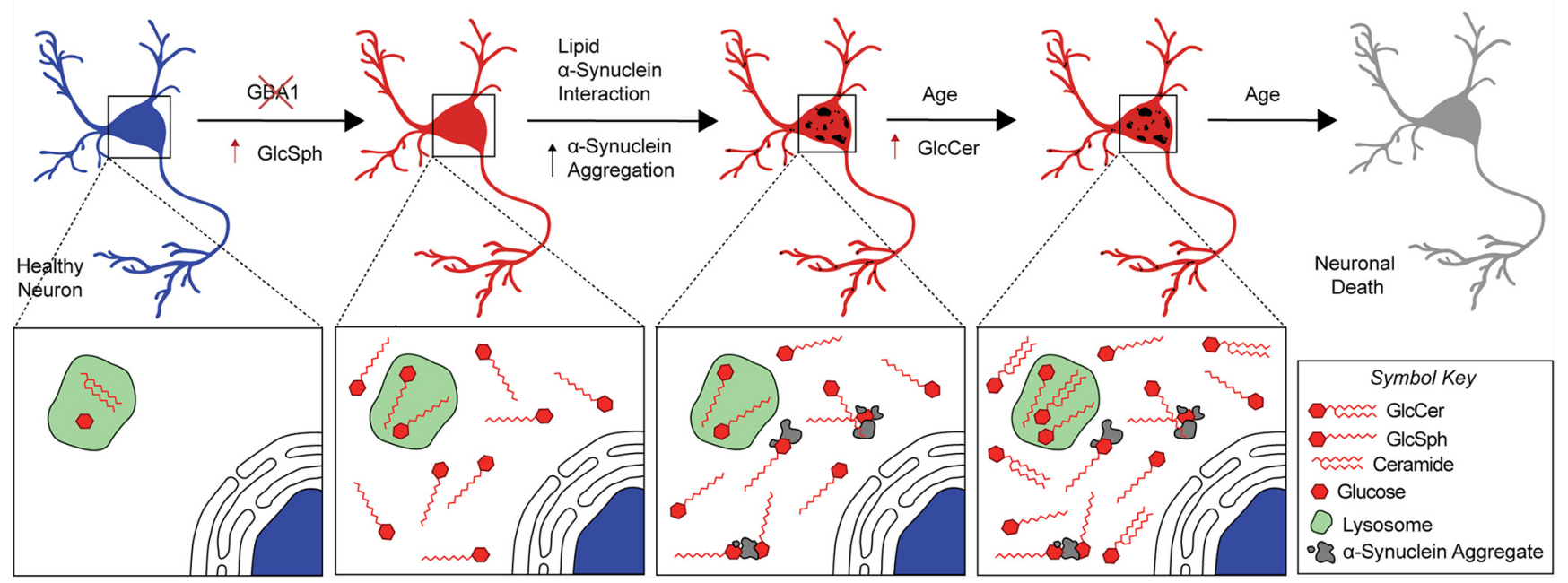

Figure 9. Model of how GD-related sphingolipids impact $\alpha$-synuclein pathology. Deletion or GD mutations in GBA leads to accumulation of GlcSph in the cytosol of neurons. Gl Sph directly interacts with $\alpha$-synuclein to promote its aggregation into distinct pathogenic oligomeric species. These pathogenic species further template intracellular $\alpha$-synuclein aggregation and may have the capacity to spread to neighboring neurons. With age, GlcCer also accumulates; and there is a decrement of Gba2 and lysosomal enzymes, exacerbating $\alpha$-synuclein pathology and proteostasis, leading to death of neurons.

al., 2008). Although it is possible the two proteins interact when $\alpha$-synuclein is degraded at lysosomes, all present evidence suggests that $\alpha$-synuclein forms cytosolic or synaptic aggregates, not intralysosomal aggregates (Okazaki et al., 1961). Lysosomal dysfunction is likely to be an important contributor in the link between GD and PD, but not the sole factor. Only GD and GBA mutants consistently increase risk of PD across the multiplicity of lysosomal diseases. A unique feature of GD, compared with other lysosomal disorders, is the accumulation of GlcCer and its bioactive metabolite GlcSph generated via activation of an alternative metabolic pathway involving acid ceramidase. Therefore, the premise of our studies is that GlcCer and GlcSph, accumulating due to a loss of GCase1 function, play a key role in mutant $G B A$ associated PD (Fig. 9). Accordingly, we have examined these sphingolipids that accumulate in GD as effectors of $\alpha$-synuclein toxicity. Importantly, these sphingolipids are present in the cytosol where $\alpha$-synuclein aggregates, making them feasible mediators of $\alpha$-synuclein pathology.

We determined that all four sphingolipids (GlcCer, GlcSph, Sph, S-1-P) promote the aggregation of WT $\alpha$-synuclein into $\beta$-sheeted conformations in vitro (Fig. 1). Similar results were obtained when these sphingolipids were added to mutant $\alpha$-synuclein, with the exception of GlcCer, which did not promote aggregation (Fig. 1G,H). These findings suggest that GlcCer's metabolites, rather than GlcCer alone, may play an integral role in influencing pathological $\alpha$-synuclein aggregation. AFM imaging and templating assays supported this notion, revealing that GlcSph and Sph induced the formation of oligomeric $\alpha$-synuclein species capable of templating endogenous $\alpha$-synuclein into aggregates in mammalian culture and human neurons (Fig. 3). Together, our in vitro results implicate GlcCer downstream metabolites as potential mediators of $\alpha$-synuclein toxicity in $G B A$-associated PD.

Molecular characterization of homozygous GD/PD mice developing early phenotypes further validated our in vitro findings. Lipidomic analysis of young homozygous GD/PD mice brains revealed that only GlcSph accumulates initially, highlighting the importance of the oligomeric $\alpha$-synuclein species formed by this sphingolipid in mediating toxicity. Furthermore, homozygous, phenotypic GD/PD mice show a clear correlation between
GlcCer and $\alpha$-synuclein pathology and the appearance of a novel, soluble aggregated $\alpha$-synuclein species in GD/PD brain relative to controls (Fig. 7). The sum of these experiments implicates GlcSph, which was found to produce toxic oligomeric $\alpha$-synuclein species in vitro and accumulated in homozygous GD/PD mouse brain, in mediating PD risk in GD patients. This conclusion is supported by previous literature, in which GlcSph was suggested to mediate brain pathology in neuropathic forms of GD, implicating a role in neurodegeneration (Nilsson and Svennerholm, 1982; Orvisky et al., 2002; Schueler et al., 2003). Notably, we and others have shown massive accumulation of GlcSph in the plasma of GD patients with biallelic GBA mutations (Dekker et al., 2011; Murugesan et al., 2016), and recent studies have also reported the accumulation of GlcSph in the substantia nigra of sporadic PD patients (Rocha et al., 2015a). GlcSph has also emerged as a promising biomarker for GD, highlighting its specificity and abundance in GD patients (Dekker et al., 2011; Mirzaian et al., 2015). These clinical data underscore the relevance of our finding that GlcSph levels mediate the risk for developing PD.

The detailed characterization and phenotyping of our longlived homozygous GD/PD mice have allowed us to investigate the mechanism by which GBA mutations confer risk for PD development. Our molecular characterization of GD/PD brain and survival data support a loss-of-function mechanism in Gba-linked PD. We showed that GlcCer accumulation and $\alpha$-synuclein aggregation are correlated in brains of both $G b a^{L 444 P / K O} S N C A^{T g}$ and $G b a^{K O / K O} S N C A^{T g}$ lines (Fig. 7), suggesting that GBA L444P mutations result in a loss of function of GCase1. This is consistent with the finding that $G b a^{L 444 P / K O}$ brains lack GCase 1 expression and enzymatic activity similar to $G b a^{K O / K O}$ (Fig. $4 D, E)$. In contrast, the $G b a^{N 370 S / K O} S N C A^{T g}$ did not phenocopy $G b a^{K O / K O} S N C A^{T g}$ and did not contribute to the mice in the homozygous GD/PD early death group. This difference in survival is likely attributed to the N370S mutation being a trafficking mutant with 50\% residual protein expression (Fig. 4D). This seems likely, as in clinical studies of PD stratified by GBA mutation, $\mathrm{N} 370 \mathrm{~S}$ had the lowest odds ratio for risk (2.2) compared with L444P (odds ratio 5.3) and other severe mutations (odds ratio 7.9) (Gan-Or et al., 2008). Some heterozygous GD/PD mice 
$\left(G b a^{L 444 P / W T} S N C A^{T g}\right.$ and $\left.G b a^{K O / W T} S N C A^{T g}\right)$ also died early with motor phenotypes, mirroring risk in patients. Previous literature has cited the intermediate risk of PD development in heterozygous GD patients as support for a gain-of-function mechanism. However, in brain homogenates of heterozygous GD mice, we see a clear age-dependent decrease in $G b a$ enzyme activity (Fig. $4 F$ ), suggesting that this leads to haploinsufficiency in the brain with age. Our conclusions have been validated by recent mouse and clinical data. Chronic systemic use of GCase1 inhibitors was shown to replicate PD phenotypes in mice, including development of $\alpha$-synuclein pathology (Rocha et al., 2015b). Importantly, heterozygote carriers of GBA mutations were shown to have age-related decline in lysosomal GCasel activity (Alcalay et al., 2014). Surprisingly, even in non-GBA-associated PD, reduced GCasel activity has been described in the substantia nigra of autopsy brains of PD patients (Gegg et al., 2012). Furthermore, GCase1 activity decreases with age in normal individuals (Rocha et al., 2015a).

Here, we propose a model where GlcSph accumulates before GlcCer in GBA-linked PD brains, and GlcSph accelerates the aggregation of $\alpha$-synuclein into pathological species (Fig. 9). We show that these aggregated $\alpha$-synuclein species are then capable of self-templating into Lewy body-like pathology. This is compounded by a decrease in lysosomal protein degradation capacity with age (Bae et al., 2015) or by a decrease in lysosomal catabolic activity, which in turn leads to increased $\alpha$-synuclein levels. These two contributions exacerbate aggregation of $\alpha$ synuclein, leading to the eventual demise of the neuron (Fig. 9).

Our cumulative data point to ASAH1 (acid ceramidase) and $G B A 2$ (glucocerebrosidase 2) as new therapeutic targets for the preventative and acute treatment of mutant $G B A$-associated PD. These novel targets have emerged as alternatives to CNSpenetrant recombinant GCase 1 enzyme replacement therapy and inhibition of GlcCer synthase (substrate reduction therapy), both of which potently reduce GlcCer and its metabolites and are currently under investigation.

\section{References}

Alcalay RN, Dinur T, Quinn T, Sakanaka K, Levy O, Waters C, Fahn S, Dorovski T, Chung WK, Pauciulo M, Nichols W, Rana HQ, Balwani M, Bier L, Elstein D, Zimran A (2014) Comparison of Parkinson risk in Ashkenazi Jewish patients with Gaucher disease and GBA heterozygotes. JAMA Neurol 71:752-757. CrossRef Medline

Babajani G, Tropak MB, Mahuran DJ, Kermode AR (2012) Pharmacological chaperones facilitate the post-ER transport of recombinant N370S mutant $\beta$-glucocerebrosidase in plant cells: evidence that N370S is a folding mutant. Mol Genet Metab 106:323-329. CrossRef Medline

Bae EJ, Yang NY, Lee C, Lee HJ, Kim S, Sardi SP, Lee SJ (2015) Loss of glucocerebrosidase 1 activity causes lysosomal dysfunction and $\alpha$-synuclein aggregation. Exp Mol Med 47:e153. CrossRef Medline

Bultron G, Kacena K, Pearson D, Boxer M, Yang R, Sathe S, Pastores G, Mistry PK (2010) The risk of Parkinson's disease in type 1 Gaucher disease. $\mathrm{J}$ Inherit Metab Dis 33:167-173. CrossRef Medline

Chandra S, Chen X, Rizo J, Jahn R, Südhof TC (2003) A broken $\alpha$-helix in folded $\alpha$-synuclein. J Biol Chem 278:15313-15318. CrossRef Medline

Chandra S, Gallardo G, Fernández-Chacón R, Schlüter OM, Südhof TC (2005) $\alpha$-Synuclein cooperates with $\operatorname{CSP} \alpha$ in preventing neurodegeneration. Cell 123:383-396. CrossRef Medline

Charrow J, Andersson HC, Kaplan P, Kolodny EH, Mistry P, Pastores G, Rosenbloom BE, Scott CR, Wappner RS, Weinreb NJ, Zimran A (2000) The Gaucher registry: demographics and disease characteristics of 1698 patients with Gaucher disease. Arch Intern Med 160:2835-2843. CrossRef Medline

Chartier-Harlin MC, Kachergus J, Roumier C, Mouroux V, Douay X, Lincoln S, Levecque C, Larvor L, Andrieux J, Hulihan M, Waucquier N, Defebvre L, Amouyel P, Farrer M, Destée A (2004) $\alpha$-Synuclein locus duplication as a cause of familial Parkinson's disease. Lancet 364:1167-1169. CrossRef Medline

Dai M, Liou B, Swope B, Wang X, Zhang W, Inskeep V, Grabowski GA, Sun Y, Pan D (2016) Progression of behavioral and CNS deficits in a viable murine model of chronic neuronopathic Gaucher disease. PLoS One 11: e0162367. CrossRef Medline

D’Angelo G, Polishchuk E, Di Tullio G, Santoro M, Di Campli A, Godi A, West G, Bielawski J, Chuang CC, van der Spoel AC, Platt FM, Hannun YA, Polishchuk R, Mattjus P, De Matteis MA (2007) Glycosphingolipid synthesis requires FAPP2 transfer of glucosylceramide. Nature 449:62-67. CrossRef Medline

Dekker N, van Dussen L, Hollak CE, Overkleeft H, Scheij S, Ghauharali K, van Breemen MJ, Ferraz MJ, Groener JE, Maas M, Wijburg FA, Speijer D, Tylki-Szymanska A, Mistry PK, Boot RG, Aerts JM (2011) Elevated plasma glucosylsphingosine in Gaucher disease: relation to phenotype, storage cell markers, and therapeutic response. Blood 118:e118-e127. CrossRef Medline

Doering T, Brade H, Sandhoff K (2002) Sphingolipid metabolism during epidermal barrier development in mice. J Lipid Res 43:1727-1733. CrossRef Medline

Elleder M (2006) Glucosylceramide transfer from lysosomes-the missing link in molecular pathology of glucosylceramidase deficiency: a hypothesis based on existing data. J Inherit Metab Dis 29:707-715. CrossRef Medline

Enquist IB, Lo Bianco C, Ooka A, Nilsson E, Månsson JE, Ehinger M, Richter J, Brady RO, Kirik D, Karlsson S (2007) Murine models of acute neuronopathic Gaucher disease. Proc Natl Acad Sci U S A 104:17483-17488. CrossRef Medline

Ferraz MJ, Marques AR, Appelman MD, Verhoek M, Strijland A, Mirzaian M, Scheij S, Ouairy CM, Lahav D, Wisse P, Overkleeft HS, Boot RG, Aerts JM (2016) Lysosomal glycosphingolipid catabolism by acid ceramidase: formation of glycosphingoid bases during deficiency of glycosidases. FEBS Lett 590:716-725. CrossRef Medline

Gallardo G, Schlüter OM, Südhof TC (2008) A molecular pathway of neurodegeneration linking [alpha]-synuclein to ApoE and $\mathrm{A}$ [beta] peptides. Nat Neurosci 11:301-308. CrossRef Medline

Gan-Or Z, Giladi N, Rozovski U, Shifrin C, Rosner S, Gurevich T, Bar-Shira A, Orr-Urtreger A (2008) Genotype-phenotype correlations between GBA mutations and Parkinson disease risk and onset. Neurology 70: 2277-2283. CrossRef Medline

Gegg ME, Burke D, Heales SJ, Cooper JM, Hardy J, Wood NW, Schapira AH (2012) Glucocerebrosidase deficiency in substantia nigra of Parkinson disease brains. Ann Neurol 72:455-463. CrossRef Medline

Grabowski GA, Petsko GA, Kolodny EH (2014) Gaucher disease. In: The online metabolic and molecular bases of inherited disease (Beaudet $\mathrm{AL}$, Vogelstein B, Kinzler KW, Antonarakis SE, Ballabio A, Gibson KM, Mitchell G, eds). New York: McGraw-Hill.

Hein LK, Meikle PJ, Hopwood JJ, Fuller M (2007) Secondary sphingolipid accumulation in a macrophage model of Gaucher disease. Mol Genet Metab 92:336-345. CrossRef Medline

Krüger R, Kuhn W, Müller T, Woitalla D, Graeber M, Kösel S, Przuntek H, Epplen JT, Schöls L, Riess O (1998) Ala30Pro mutation in the gene encoding $\alpha$-synuclein in Parkinson's disease. Nat Genet 18:106-108. CrossRef Medline

Lesage S, Anheim M, Letournel F, Bousset L, Honoré A, Rozas N, Pieri L, Madiona K, Dürr A, Melki R, Verny C, Brice A (2013) G51D $\alpha$-synuclein mutation causes a novel Parkinsonian-pyramidal syndrome. Ann Neurol 73:459-471. CrossRef Medline

Lobley A, Whitmore L, Wallace BA (2002) DICHROWEB: an interactive website for the analysis of protein secondary structure from circular dichroism spectra. Bioinformatics 18:211-212. CrossRef Medline

Luk KC, Song C, O'Brien P, Stieber A, Branch JR, Brunden KR, Trojanowski JQ, Lee VM (2009) Exogenous $\alpha$-synuclein fibrils seed the formation of Lewy body-like intracellular inclusions in cultured cells. Proc Natl Acad Sci U S A 106:20051-20056. CrossRef Medline

Martinez Z, Zhu M, Han S, Fink AL (2007) GM1 specifically interacts with alpha-synuclein and inhibits fibrillation. Biochemistry 46:1868-1877. CrossRef Medline

Mazzulli JR, Xu YH, Sun Y, Knight AL, McLean PJ, Caldwell GA, Sidransky E, Grabowski GA, Krainc D (2011) Gaucher disease glucocerebrosidase and $\alpha$-synuclein form a bidirectional pathogenic loop in synucleinopathies. Cell 146:37-52. CrossRef Medline 
Mirzaian M, Wisse P, Ferraz MJ, Gold H, Donker-Koopman WE, Verhoek M, Overkleeft HS, Boot RG, Kramer G, Dekker N, Aerts JM (2015) Mass spectrometric quantification of glucosylsphingosine in plasma and urine of type 1 Gaucher patients using an isotope standard. Blood Cells Mol Dis 54:307-314. CrossRef Medline

Mistry PK, Liu J, Yang M, Nottoli T, McGrath J, Jain D, Zhang K, Keutzer J, Chuang WL, Chuang WL, Mehal WZ, Zhao H, Lin A, Mane S, Liu X, Peng YZ, Li JH, Agrawal M, Zhu LL, Blair HC, et al. (2010) Glucocerebrosidase gene-deficient mouse recapitulates Gaucher disease displaying cellular and molecular dysregulation beyond the macrophage. Proc Natl Acad Sci U S A 107:19473-19478. CrossRef Medline

Mistry PK, Liu J, Sun L, Chuang WL, Yuen T, Yang R, Lu P, Zhang K, Li J, Keutzer J, Stachnik A, Mennone A, Boyer JL, Jain D, Brady RO, New MI, Zaidi M (2014) Glucocerebrosidase 2 gene deletion rescues type 1 Gaucher disease. Proc Natl Acad Sci U S A 111:4934-4939. CrossRef Medline

Mizukami H, Mi Y, Wada R, Kono M, Yamashita T, Liu Y, Werth N, Sandhoff R, Sandhoff K, Proia RL (2002) Systemic inflammation in glucocerebrosidase-deficient mice with minimal glucosylceramide storage. J Clin Invest 109:1215-1221. CrossRef Medline

Murugesan V, Chuang WL, Liu J, Lischuk A, Kacena K, Lin H, Pastores GM, Yang R, Keutzer J, Zhang K, Mistry PK (2016) Glucosylsphingosine is a key biomarker of Gaucher disease. Am J Hematol 91:1082-1089. CrossRef Medline

Nilsson O, Svennerholm L (1982) Accumulation of glucosylceramide and glucosylsphingosine (psychosine) in cerebrum and cerebellum in infantile and juvenile Gaucher disease. J Neurochem 39:709-718. CrossRef Medline

Nussbaum RL, Ellis CE (2003) Alzheimer's disease and Parkinson's disease. N Engl J Med 348:1356-1364. CrossRef Medline

Okazaki H, Lipkin LE, Aronson SM (1961) Diffuse intracytoplasmic ganglionic inclusions (Lewy type) associated with progressive dementia and quadriparesis in flexion. J Neuropathol Exp Neurol 20:237-244. CrossRef Medline

Orvisky E, Park JK, LaMarca ME, Ginns EI, Martin BM, Tayebi N, Sidransky E (2002) Glucosylsphingosine accumulation in tissues from patients with Gaucher disease: correlation with phenotype and genotype. Mol Genet Metab 76:262-270. CrossRef Medline

Peelaerts W, Bousset L, Van der Perren A, Moskalyuk A, Pulizzi R, Giugliano M, Van den Haute C, Melki R, Baekelandt V (2015) alpha-Synuclein strains cause distinct synucleinopathies after local and systemic administration. Nature 522:340-344. CrossRef Medline

Polymeropoulos MH, Lavedan C, Leroy E, Ide SE, Dehejia A, Dutra A, Pike B, Root H, Rubenstein J, Boyer R, Stenroos ES, Chandrasekharappa S, Athanassiadou A, Papapetropoulos T, Johnson WG, Lazzarini AM, Duvoisin RC, Di Iorio G, Golbe LI, Nussbaum RL (1997) Mutation in the $\alpha$-synuclein gene identified in families with Parkinson's disease. Science 276:2045-2047. CrossRef Medline

Proukakis C, Dudzik CG, Brier T, MacKay DS, Cooper JM, Millhauser GL, Houlden H, Schapira AH (2013) A novel alpha-synuclein missense mutation in Parkinson disease. Neurology 80:1062-1064. CrossRef Medline

Provencher SW, Glöckner J (1981) Estimation of globular protein secondary structure from circular dichroism. Biochemistry 20:33-37. CrossRef Medline

Recasens A, Dehay B, Bové J, Carballo-Carbajal I, Dovero S, Pérez-Villalba A, Fernagut PO, Blesa J, Parent A, Perier C, Fariñas I, Obeso JA, Bezard E, Vila M (2014) Lewy body extracts from Parkinson disease brains trigger alpha-synuclein pathology and neurodegeneration in mice and monkeys. Ann Neurol 75:351-362. CrossRef Medline

Rocha EM, Smith GA, Park E, Cao H, Brown E, Hallett P, Isacson O (2015a) Progressive decline of glucocerebrosidase in aging and Parkinson's disease. Ann Clin Transl Neurol 2:433-438. CrossRef Medline

Rocha EM, Smith GA, Park E, Cao H, Graham AR, Brown E, McLean JR, Hayes MA, Beagan J, Izen SC, Perez-Torres E, Hallett PJ, Isacson O (2015b) Sustained systemic glucocerebrosidase inhibition induces brain alpha-synuclein aggregation, microglia and complement $\mathrm{Clq}$ activation in mice. Antioxid Redox Signal 23:550-564. CrossRef Medline

Saito Y, Kawashima A, Ruberu NN, Fujiwara H, Koyama S, Sawabe M, Arai T, Nagura H, Yamanouchi H, Hasegawa M, Iwatsubo T, Murayama S (2003) Accumulation of phosphorylated alpha-synuclein in aging human brain. J Neuropathol Exp Neurol 62:644-654. CrossRef Medline

Schueler UH, Kolter T, Kaneski CR, Blusztajn JK, Herkenham M, Sandhoff K,
Brady RO (2003) Toxicity of glucosylsphingosine (glucopsychosine) to cultured neuronal cells: a model system for assessing neuronal damage in Gaucher disease type 2 and 3. Neurobiol Dis 14:595-601. CrossRef Medline

Sidransky E, Nalls MA, Aasly JO, Aharon-Peretz J, Annesi G, Barbosa ER, Bar-Shira A, Berg D, Bras J, Brice A, Chen CM, Clark LN, Condroyer C, De Marco EV, Dürr A, Eblan MJ, Fahn S, Farrer MJ, Fung HC, Gan-Or Z, et al. (2009) Multicenter analysis of glucocerebrosidase mutations in Parkinson's disease. N Engl J Med 361:1651-1661. CrossRef Medline

Singleton AB, Farrer M, Johnson J, Singleton A, Hague S, Kachergus J, Hulihan M, Peuralinna T, Dutra A, Nussbaum R, Lincoln S, Crawley A, Hanson M, Maraganore D, Adler C, Cookson MR, Muenter M, Baptista M, Miller D, Blancato J, et al. (2003) $\alpha$-Synuclein locus triplication causes Parkinson's disease. Science 302:841. CrossRef Medline

Spillantini MG, Schmidt ML, Lee VM, Trojanowski JQ, Jakes R, Goedert M (1997) $\alpha$-Synuclein in Lewy bodies. Nature 388:839-840. CrossRef Medline

Tsuji S, Choudary PV, Martin BM, Stubblefield BK, Mayor JA, Barranger JA, Ginns EI (1987) A mutation in the human glucocerebrosidase gene in neuronopathic Gaucher's disease. N Engl J Med 316:570-575. CrossRef Medline

Tsuji S, Martin BM, Barranger JA, Stubblefield BK, LaMarca ME, Ginns EI (1988) Genetic heterogeneity in type 1 Gaucher disease: multiple genotypes in Ashkenazic and non-Ashkenazic individuals. Proc Natl Acad Sci U S A 85:2349-2352. CrossRef Medline

van Stokkum IH, Spoelder HJ, Bloemendal M, van Grondelle R, Groen FC (1990) Estimation of protein secondary structure and error analysis from circular dichroism spectra. Anal Biochem 191:110-118. CrossRef Medline

Vargas KJ, Makani S, Davis T, Westphal CH, Castillo PE, Chandra SS (2014) Synucleins regulate the kinetics of synaptic vesicle endocytosis. J Neurosci 34:9364-9376. CrossRef Medline

Whitmore L, Wallace BA (2004) DICHROWEB, an online server for protein secondary structure analyses from circular dichroism spectroscopic data. Nucleic Acids Res 32:W668-W673. CrossRef Medline

Whitmore L, Wallace BA (2008) Protein secondary structure analyses from circular dichroism spectroscopy: methods and reference databases. Biopolymers 89:392-400. CrossRef Medline

Winner B, Jappelli R, Maji SK, Desplats PA, Boyer L, Aigner S, Hetzer C, Loher T, Vilar M, Campioni S, Tzitzilonis C, Soragni A, Jessberger S, Mira H, Consiglio A, Pham E, Masliah E, Gage FH, Riek R (2011) In vivo demonstration that $\alpha$-synuclein oligomers are toxic. Proc Natl Acad Sci U S A 108:4194-4199. CrossRef Medline

Wong K, Sidransky E, Verma A, Mixon T, Sandberg GD, Wakefield LK, Morrison A, Lwin A, Colegial C, Allman JM, Schiffmann R (2004) Neuropathology provides clues to the pathophysiology of Gaucher disease. Mol Genet Metab 82:192-207. CrossRef Medline

Xu YH, Quinn B, Witte D, Grabowski GA (2003) Viable mouse models of acid beta-glucosidase deficiency. Am J Pathol 163:2093-2101. CrossRef Medline

Yap TL, Gruschus JM, Velayati A, Westbroek W, Goldin E, Moaven N, Sidransky E, Lee JC (2011) $\alpha$-Synuclein interacts with glucocerebrosidase providing a molecular link between Parkinson and Gaucher diseases. J Biol Chem 286:28080-28088. CrossRef Medline

Yildiz Y, Matern H, Thompson B, Allegood JC, Warren RL, Ramirez DM, Hammer RE, Hamra FK, Matern S, Russell DW (2006) Mutation of $\beta$-glucosidase 2 causes glycolipid storage disease and impaired male fertility. J Clin Invest 116:2985-2994. CrossRef Medline

Zarranz JJ, Alegre J, Gómez-Esteban JC, Lezcano E, Ros R, Ampuero I, Vidal L, Hoenicka J, Rodriguez O, Atarés B, Llorens V, Gomez Tortosa EG, del Ser T, Muñoz DG, de Yebenes JG (2004) The new mutation, E46K, of $\alpha$-synuclein causes parkinson and Lewy body dementia. Ann Neurol 55: 164-173. CrossRef Medline

Zhang YQ, Henderson MX, Colangelo CM, Ginsberg SD, Bruce C, Wu T, Chandra SS (2012) Identification of CSPalpha clients reveals a role in dynamin 1 regulation. Neuron 74:136-150. CrossRef Medline

Zhang Y, Pak C, Han Y, Ahlenius H, Zhang Z, Chanda S, Marro S, Patzke C, Acuna C, Covy J, Xu W, Yang N, Danko T, Chen L, Wernig M, Südhof TC (2013) Rapid single-step induction of functional neurons from human pluripotent stem cells. Neuron 78:785-798. CrossRef Medline 